\title{
Benzo[1,2,3]dithiazole Compounds: A History of Synthesis and Their Renewed Applicability in Materials and Synthetic Chemistry, Originating from the Herz Reaction
}

\author{
Alexander J. Nicholls *(D) and Ian R. Baxendale (D) \\ Department of Chemistry, University of Durham, South Road, Durham DH1 3LE, UK; \\ i.r.baxendale@durham.ac.uk \\ * Correspondence: alexander.j.nicholls@durham.ac.uk
}

check for updates

Citation: Nicholls, A.J.; Baxendale, I.R. Benzo[1,2,3]dithiazole

Compounds: A History of Synthesis and Their Renewed Applicability in Materials and Synthetic Chemistry, Originating from the Herz Reaction Reactions 2021, 2, 175-208. https:/ / doi.org/10.3390/reactions2030013

Academic Editors: Silvana Pedatella and Dmitry Yu. Murzin

Received: 3 May 2021

Accepted: 24 June 2021

Published: 29 June 2021

Publisher's Note: MDPI stays neutral with regard to jurisdictional claims in published maps and institutional affiliations.

Copyright: (c) 2021 by the authors. Licensee MDPI, Basel, Switzerland. This article is an open access article distributed under the terms and conditions of the Creative Commons Attribution (CC BY) license (https:/ / creativecommons.org/licenses/by/ $4.0 /)$.

\begin{abstract}
The benzo[1,2,3]dithiazole is a unique heteroaromatic functionality whose conjugated profile instils some fascinating electronic properties. This has been historically recognized in the design and manufacture of organic dyes early last century. Although, with the benefit of increased diagnostic techniques and improved understanding, these structures are attracting greater attention in additional research settings, including applications as organic radicals and semiconductors. In addition, the benzodithiazole functionality has been shown to be a valuable synthetic intermediate in the preparation of a variety of other privileged aromatic and heteroaromatic targets, many of which are important APIs. In this review, the authors aim to critically analyse the potential applicability of these compounds to the fields of not only small-scale laboratory synthetic and medicinal chemistry but also commercial-scale processes and increasingly materials chemistry.
\end{abstract}

Keywords: thiazole; disulfur dichloride; Herz reaction; heterocycle formation; organic radical anion; semiconductor; dye

\section{Introduction to Benzo[1,2,3]dithiazole Compounds}

The benzo[1,2,3]dithiazole is a rare and enigmatic heterocycle (Figure 1), which at first glance has similarity to the more common benzothiazole structure, with the carbon at the 2-position exchanged for sulphur. In addition, there also exists the isomeric benzo[1,3,2]dithiazole, which, although also displaying some similar properties and applications [1-4], will not be covered in this review owing largely to the differences in synthesis [5] (and from here forward for simplicity, 'benzodithiazole' will refer only to the $[1,2,3]$ dithiazole derivatives).<smiles>c1ccc2ssc2c1</smiles>

Benzo[1,2,3]dithiazole<smiles>c1ccc2c(c1)SNS2</smiles>

Benzo[1,3,2]dithiazole<smiles></smiles>

Benzo[1,3]thiazole
Figure 1. The structure and parent numbering system for benzo[1,2,3]dithiazole, benzo[1,3,2]dithiazole and benzothiazole.

While all but neglected as a synthetic intermediate in API and bulk/fine chemicals, the valuable electronic properties of the dithiazole structures have engendered renewed interest in recent years. As a result, the general benzo[1,2,3]dithiazole structure appears roughly equally in both the scientific and patent literature over the previous ten years as it did in the near 100 years of its preceding existence [6]. Despite a renewed interest in the compounds recently, much of the synthetic methods and understanding remain 
mostly transcribed from the original literature (early-to-mid last century). This review aims to highlight their interesting synthetic chemistry and signpost some of the most popular end-use applications.

\subsection{Categorisation of Benzo[1,2,3]dithiazole Compounds}

The benzo[1,2,3] dithiazole structure exists most commonly in three different forms with vastly different characteristic properties: the benzodithiazolium cation, the neutral compound and the benzodithiazoyl radical. All three are reversibly interconverted through simple chemical transformations [4,7]. The benzodithiazolium cation is a planar, 10- $\pi$ aromatic system and is the most facile benzo[1,2,3]dithaizole to generate experimentally. Supported by a counterion (most commonly chloride), it is generically referred to as a 'Herz salt,' and these compounds are generally amorphous and are sparingly soluble in most organic solvents and aqueous media unless there are large substituents or counterions present. In such circumstances, crystalline polymorphs have been isolated, allowing analysis of the solid structure by X-ray diffraction (XRD) analysis [8]. The second form of benzo[1,2,3]dithiazoles, the neutral compounds, can normally only form when specific substituents are located at the 2 or 6 positions; otherwise, the molecule's lack of conjugation makes the structure too high in energy. The most common examples being the 2-sulfoxides and 6-malononitrile derivatives. These compounds generally replicate the Herz salts in their physical properties (high melting solid, poor solubility), although they can have extremely different absorption properties, notably the intense-purple appearance of the S-sulfoxides. These materials tend to be bench-stable, whereas the Herz salts are found to gradually hydrolyse to the 2-sulfoxides in the presence of moisture. Finally, there are the $11-\pi$ 'Herz radicals,' which, in contrast, are highly soluble in a range of organic solvents. While unquestionably reactive intermediates, they are often stable in degassed, non-polar solvents and readily detected by ESR and their distinctive absorption spectra.

Overall, all three benzo[1,2,3]dithiazole-derived structures (Figure 2) have very different properties, with each possessing unique and specialised attributes, resulting in different applications in synthesis and materials chemistry.<smiles>Cl[Se]=Nc1ccccc1</smiles>

Benzodithiazolium Chloride 'Herz Salt'

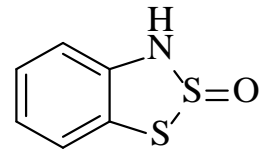<smiles>N#CC(C#N)=c1ccc2c(c1)SSN=2</smiles>

Stable, neutral benzodithiazoles<smiles></smiles>

\section{Benzodithiazoyl}

'Herz Radical'

Figure 2. The three principal stable forms that benzodithiazole compounds generally exist as.

\subsection{Formation and Characterisation of Benzo[1,2,3]dithiazole Compounds}

With the exception of the occasional ring-contraction procedure [9], benzodithiazole rings (e.g., 2, 3) are typically formed using the historical Herz reaction or, to a lesser extent, the reaction of a 2-aminothiophenol (e.g., 3a) with thionyl chloride (Scheme 1) [10-12]. The first product is the Herz salt, from which other derivatives can be readily generated in simple, single-step transformations, which will be discussed in detail later. Characterisation of benzodithiazole compounds right across the series has proven challenging due to variable stabilities, purification difficulties and often poor solubilities, although all have full characterisation data (the Herz radical, of course, as a solution). Historically the Lewis structures of the first Herz salts and neutral forms were reasoned by derivatisation (reacting to form known entities) but were later characterised by elemental composition analysis, absorbance spectroscopy, mass spectrometry and finally, NMR. Due to the nature of the material, the Herz radicals have been identified by ESR spectroscopy, and some solid Herz compounds and salts have been further studied by XRD. In general, a review of the literature indicates that Herz salts with small monoatomic counterions generate amorphous 
solids, but well-resolved structures are available with larger counterions such as $\mathrm{SbCl}_{6}{ }^{-}(4 \mathbf{a}$, Figure 3a) and $\mathrm{BF}_{4}{ }^{-}$. There are written descriptions of benzodithiazole-2-sulfoxides as having 'crystalline' forms $[7,13,14]$; however, a published XRD structure remains unavailable. Instead, there are abundant examples of other solved neutral benzodithiazole structures (e.g., $4 \mathbf{b}$, Figure $3 b$ ) $[4,8,15]$. In these structures, the $\pi$-interactions from the benzodithiazole rings are readily apparent from these flat molecules stacking atop one-another.

Herz Reaction (first Stage) [9]
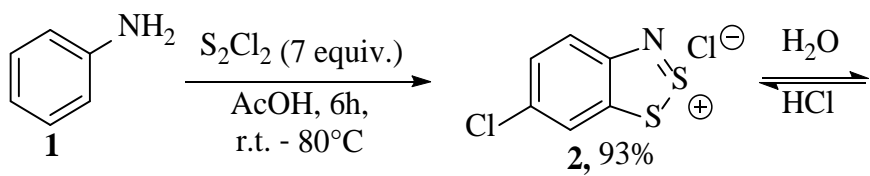<smiles>O=S1Nc2ccc(Cl)cc2S1</smiles>

Formation with Thionyl Chloride [10]

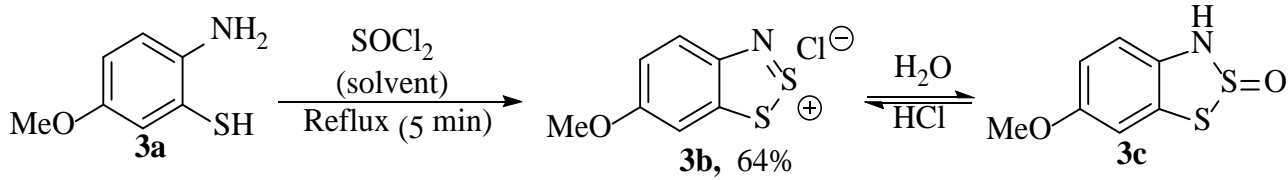

Scheme 1. An example of benzodithiazole formation using both the Herz reaction and with thionyl chloride $[10,16]$.<smiles>Clc1nc2c(Br)cc(Br)cc2s1</smiles>

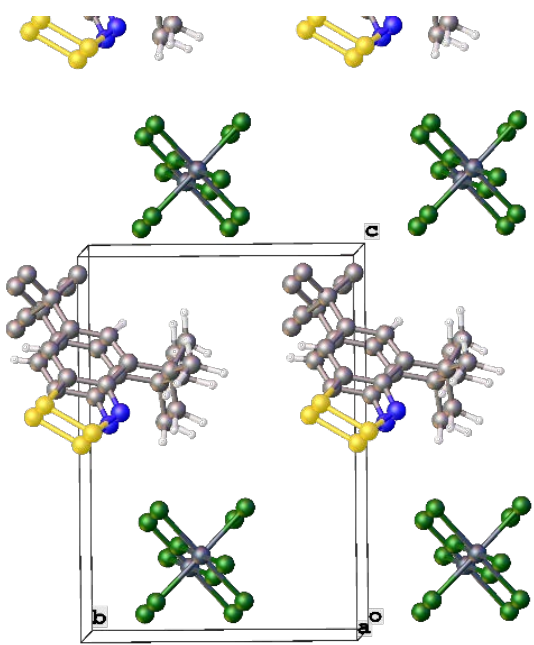

(a)<smiles></smiles>

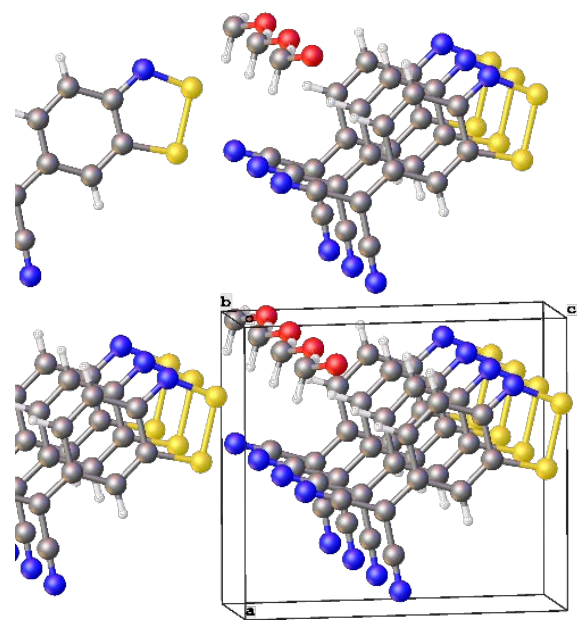

(b)

Figure 3. The crystal structures and unit cells of (a) 4,6-di-t-butyl-1,2,3-benzodithiazolium hexachloroantimony (4a) [8] and (b) 6H-1,2,3-benzodithiazol-6-ylidenemalononitrile tetrahydrofuran solvate (4b) [17].

\section{Synthesis of Benzodithiazole Compounds Using the Herz Reaction}

As indicated below (Scheme 2), structures, such as $\mathbf{2}$ or 3, derive their name from the chemical transformation used in their preparation. Named after its discoverer, Richard Herz, the Herz reaction was first patented [18] in 1913 and published in subsequent journal articles 10 years later, as detailed [19]. It relates to the reaction of various anilines with disulfur dichloride (also known as sulphur monochloride) in a medium of acetic acid 
to form 'Herz salts,' e.g., compound 2 (Scheme 2) [20]. These compounds readily and reversibly react with water to form the sulfone structure 3 (faster in the presence of mild alkaline) and revert to the Herz chloride salt upon treatment with strong $\mathrm{HCl}$ [7]. The S-oxide 3 can be further manipulated to produce other structures [21]; the simplest way is to use alkaline hydrolysis, leading to ortho-aminothiophenols, as will be elaborated in detail subsequently [22]. Both the intermediate compounds and the final 2-aminothiophenol hydrolysis products have a variety of uses, but the objective cited by the literature at the time was to make scaffolds for use in the synthesis of dyes $[19,23]$. The combination and reaction of aniline (1) and sulphur monochloride had been reported in a publication substantially predating (1873 - see Section 2.2) that of the Herz reaction [24]; however, the product was only described as a 'violet-brown dye' and was not characterised.

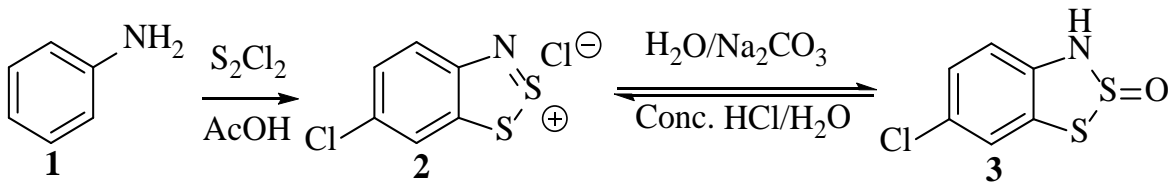

Scheme 2. The Herz reaction applied to aniline (1).

The Herz reaction is often accompanied by chlorination of the para position of the benzo[1,2,3] dithiazole relative to the amine, including through replacement of some substituents, such as nitro groups that occupy this site in the aniline starting material [23]. The resultant Herz compounds (e.g., $\mathbf{2}$ and $\mathbf{3}$ ) are reported for several derivatives with isolated yields in the literature [14]. However, conclusive proof of the full structure, including the 5-membered ring, was not presented. Instead, derivatization, for example, through hydrolysis to form the aminothiol, and comparison to alternative synthesis methods was used to elucidate the structure. The dithiazole ring has subsequently been confirmed as correctly hypothesised by unanimous methods such as XRD analysis [25].

\subsection{History and Contributions to Understanding and Mechanism}

The very first record of the Herz reaction is the aforementioned occurrence in 1873 [26] when German chemist, Claus, reported mixing aniline with disulfur dichloride, noting a 'violent' reaction with a purple compound as the product. The reactivity was complicated by the use of carbon disulphide as the reaction medium, and the benzodithiazole compound was not identified. The first representation of the [1,2,3]dithiazole ring appears in Herz's patent dating 1914 [18], an impressive feat at the time to correctly identify this entirely novel heterocycle. At the time of discovery, the mechanism was not well understood, with little being recorded in the original literature, other than the not-wholly-correct claim that the S-S-Cl moiety shown in the product originates directly from the disulfur dichloride reagent [19] (the $\mathrm{Cl}$ is a counterion not associated with a particular $\mathrm{S}$ atom). An attempt was made by Bezzubets and Rozina to understand the first stage of the reaction [27]; however, their postulation was based on an incorrect Lewis structure for the sulphur monochloride (5a, Figure 4).<smiles>S=S(Cl)Cl</smiles><smiles>SSSCl</smiles>

Figure 4. The assumed Lewis structure of sulphur monochloride at the time of the investigation by Bezzubets and Rozina, 5a [27] and the currently accepted Lewis structure of disulfur dichloride, $5 \mathbf{b}$ [28].

Later, Gompper et al. attempted to devise a more comprehensive understanding. Their findings are outlined in summary in Scheme 3 [29]. The initiating step involves the polarised $\mathrm{S}-\mathrm{Cl}$ bonds, which ensures that the $\mathrm{S}$ atom is electrophilic and hence can be 
attacked by nucleophilic nitrogen. However, additional speculation that the aromatic chlorination occurs by the action of sulphur monochloride $\left(\mathrm{S}_{\mathrm{E}} \mathrm{Ar}\right)$ was found to be inaccurate, and there was no account for the fact that electron-withdrawing groups in this position were replaced by a chloride [22]. Although, in general, this proposed sequence proved helpful in explaining many of the experimental results, it was but a beginning to the full understanding of the sequence.
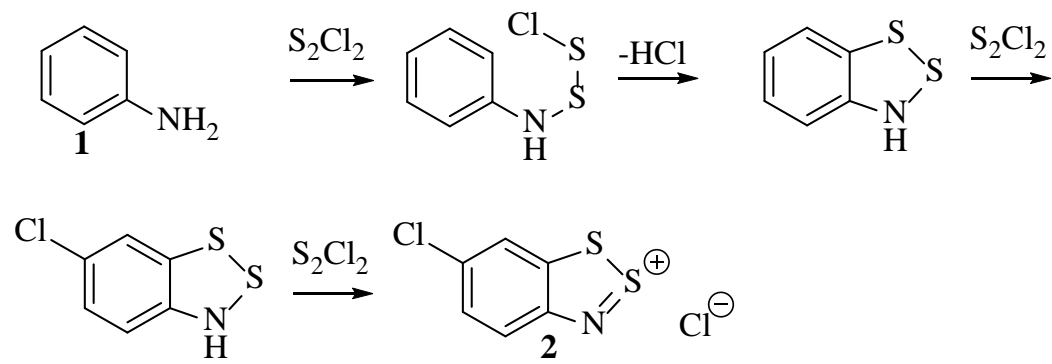

Scheme 3. The first postulated sequence of intermediates in the Herz reaction from Gompper et al. [29].

In a successive publication by Huestis et al. [16], studies were conducted to better understand the aromatic chlorination event of the process. A systematic investigation was undertaken with the aim to first establish whether the non-chlorinated 1,2,3-dithiazole (Scheme 4, 2a) was an intermediate. This was achieved by reacting these (previously synthesised) compounds directly under the conditions of the Herz reaction. Thus, hypothesising: if the chlorinated product was found, this would add credence that the chlorination was promoted by disulfur dichloride and that the chlorination was occurring after the initial formation of the 1,2,3-dithiazole (e.g., 2a) [16]. This is one of the first reports of a mechanistic investigation into the Herz reaction, and although the conclusions are limited, it was determined that this structure (Scheme 4, 2a) was not intermediate because it did not react under these conditions [16].

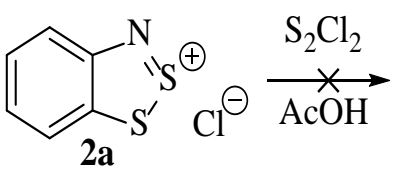<smiles></smiles>

Scheme 4. A finding of Huestis et al. that suggests 2a is not an intermediate of the Herz reaction [16].

A subsequent study by Hope et al. defines the Herz reaction in terms of three separate stages [22]. The stages were:

(1) Formation of the 5-membered 1,2,3-dithiazole ring.

(2) Chlorination of the carbon para to the amine (if possible) or replacement of electronwithdrawing groups that are ortho or para to the amine (Scheme 5).

(3) Oxidation of the thiophenol sulphur to form the salt.

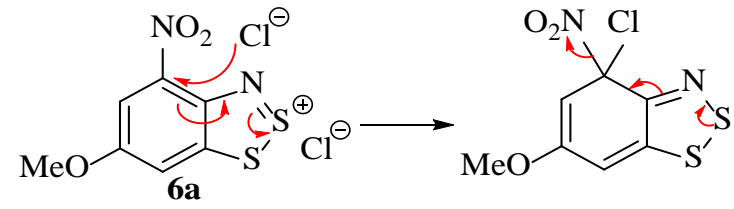<smiles></smiles>

Scheme 5. The replacement of electron-withdrawing (but not electron-donating) substituents by chloride.

Interestingly, they discovered that free chlorine $\left(\mathrm{Cl}_{2}\right)$ was present in the reaction and deduced that this was more likely to be the chlorinating agent for the ring, as sulphur 
monochloride is not sufficiently electrophilic (at the chlorides) to act as a powerful chlorinating agent [22]. They also concluded that the chlorination stage cannot occur after the Herz salt $\mathbf{2}$ has already formed, as previously suggested by Huetis, because the azathiolium group deactivates the ring towards electrophilic substitution as it is electron deficient. While the chlorination of a vacant para position was still believed to be an electrophilic mechanism, the replacement of other groups by chloride was instead proposed as a nucleophilic substitution, occurring due to the presence and activation by the electronwithdrawing benzodithiazolium. This reasoning represents a significant improvement in comprehension, and it was correct to deduce that $\mathrm{S}_{2} \mathrm{Cl}_{2}$ is not the direct source of the chloride, but it was still not understood how the chloride actually originated.

This new hypothesis by Hope involving a free chloride ion undergoing nucleophilic substitution of a group on the ring, rather than electrophilic substitution by disulfur dichloride, is supported by results obtained when free $\mathrm{Br}_{2}$ was added to the reaction mixture during the Herz reaction resulting in the isolation of the Herz bromide salt as the product (Scheme 6) [22]. This led to the theory that the aromatic $\mathrm{C}-\mathrm{Cl}$ bond forms not from reaction with $\mathrm{S}_{2} \mathrm{Cl}_{2}$ but with $\mathrm{Cl}_{2}$. The observation that $\mathrm{Cl}_{2}$ could be detected in the conditions of the Herz reactions made this more likely [22].<smiles>COc1ccc(Nc2cc(OC)c(C(=O)O)cc2Cl)c([N+](=O)[O-])c1</smiles><smiles>COc1ccc(Nc2ccc(OC)cc2[N+](=O)[O-])c(Br)c1</smiles>

Scheme 6. The effect of using bromine in addition with the normal Herz reaction conditions on the major product isolated.

The detection of free $\mathrm{Cl}_{2}$ in the reaction could originate from the direct equilibrium of $\mathrm{S}_{2} \mathrm{Cl}_{2}$, although this was considered unlikely compared to the liberation of free $\mathrm{Cl}_{2}$ by reaction with the protonated structure $2 \mathrm{c}$ (Scheme 7). The process is likely prevalent enough for the mechanism to proceed, provided the sulphur monochloride is in excess (which it is in every recorded literature example, typically 5-7 equivalents is used).

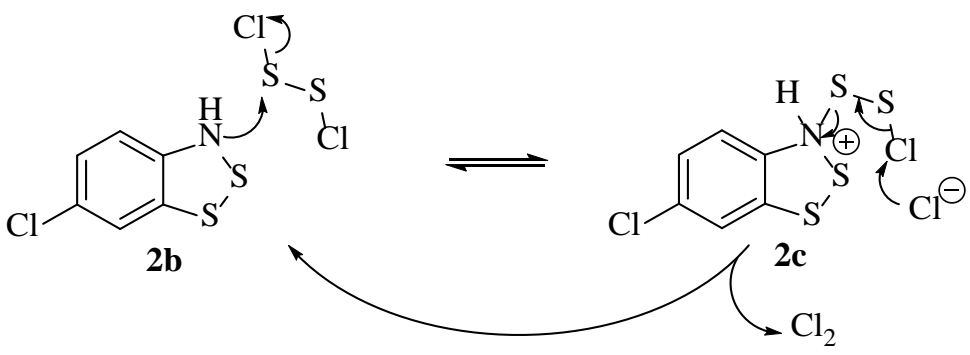

Scheme 7. The postulated mecahnism to explain the generation of $\mathrm{Cl}_{2}$ [22].

Although Hope correctly reasoned the $\mathrm{S}_{\mathrm{N}} \mathrm{Ar}$ of leaving groups with chloride, the explanation for the $\mathrm{C}-\mathrm{Cl}$ bond formation para to the nitrogen of the Herz compound if unsubstituted relies on electrophilic aromatic substitution with $\mathrm{Cl}_{2}$ (Scheme 8). It is unlikely the aromatic ring is sufficiently electron-rich for this transformation. There is instead evidence that the chloride attack is much the same whether or not there is a substituent at the para position: $\mathrm{S}_{\mathrm{N}} \mathrm{Ar}$. In summary, Hope's study came very close to the 
correct sequence but just fell short when it came to explaining the $p$-chlorination in the absence of another substituent.<smiles>C[I+](C)Cc1ccc2c(c1)SSN2</smiles><smiles>Clc1ccc2c(c1)SS(Cl)(Cl)N2</smiles><smiles></smiles>

Scheme 8. The postulation for the mechanism of the Herz reaction by Hope et al. [22].

\subsection{Proposed Mechanism of the Herz Reaction}

To date, there still remains no comprehensive model in the literature that accounts for all the experimental results as well as the resulting overall equation (Scheme 9). Therefore, the postulated mechanism as shown in Scheme 10 is our attempt at bringing together all the experimental evidence from across the existing literature.

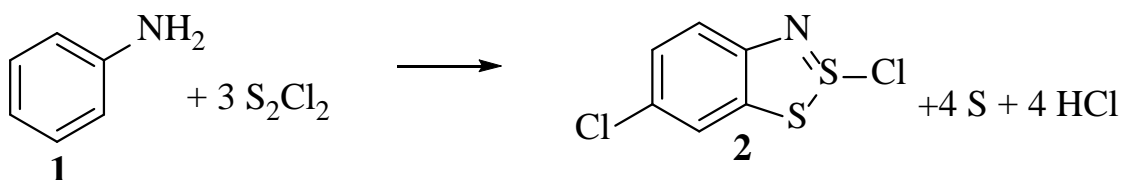

Scheme 9. The balanced equation for the first stage of the Herz reaction.

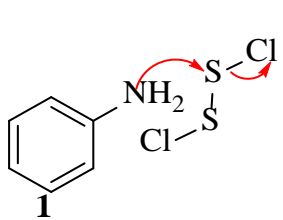<smiles></smiles><smiles>ClS1=Nc2ccccc2S1</smiles>

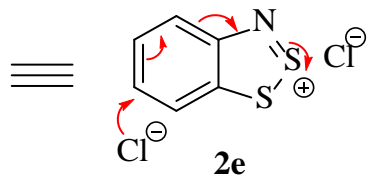<smiles></smiles>

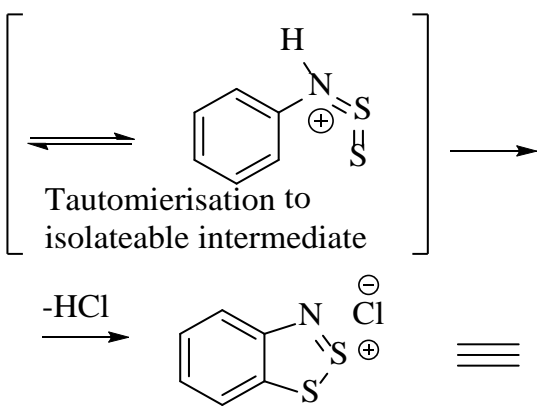

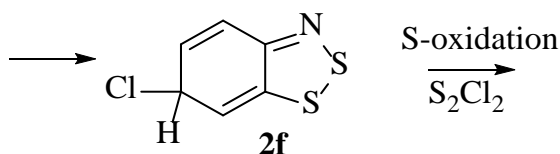

Scheme 10. A new postulated mechanism, taking into account all current literature results to explain the sequence of the Herz reaction. 
The fundamental difference between this and earlier propositions is in the carbonchlorination stage, which occurs after oxidation of the sulphur and by a chloride nucleophile rather than some form of chlorine electrophile. This mechanism does not include the role of free $\mathrm{Cl}_{2}$ because there is no evidence to suggest this species is critical in the mechanism, only that it exists as a by-product [22]. It could be that the free $\mathrm{Cl}_{2}$ can also perform the chlorination of the sulphur in $\mathbf{2} \mathbf{d}$ as an alternative to the disulfur dichloride. An implication of this mechanism is that three equivalents of $\mathrm{S}_{2} \mathrm{Cl}_{2}$ are required for the transformation (typically, more than 5 are used in the literature). Despite the low purchase price of $\mathrm{S}_{2} \mathrm{Cl}_{2}$, this could render the scheme uneconomical for many industrial applications, even more so considering the large sulphur and hydrochloric acid waste (low overall atom economy).

A difficulty in the compilation of this mechanism was the $\mathrm{C}-\mathrm{Cl}$ bond formation pertaining to compound $\mathbf{2} \mathbf{f}$ when the study by Huetis [16] ruled out $\mathbf{2 e}$ as an intermediate by trying to react it directly with $\mathrm{S}_{2} \mathrm{Cl}_{2}$. Further developments, such as the practical and computation study by Akulin et al. [10], suggest the feasibility that structure $2 \mathbf{e}$ could be attacked by a chloride anion at the 6-position as it carries a partial positive charge of $0.14 \mathrm{eV}$ (Figure 5). The reason that 6-chlorination is observed as part of the complete Herz reaction, but not by Huestis when reacting $2 \mathbf{e}$ with $\mathrm{S}_{2} \mathrm{Cl}_{2}$ is rationalised by the action of the chloride anion that is required for this phenomenon. The amount of free chloride available is only sufficient when generated during the earlier stages of the Herz reaction and not when $2 \mathbf{e}$ is mixed with $\mathrm{S}_{2} \mathrm{Cl}_{2}$. Another important aspect of consideration is that in some instances, a thiosulfinyl-aniline $(\mathrm{Ar}-\mathrm{N}=\mathrm{S}=\mathrm{S})$ intermediate is reported in the place of the chloro-disulphide [30-32]. Instinctively we were not keen on the $\mathrm{S}=\mathrm{S}$ double bonds, although this functionality has several isolated examples when formed under related conditions. The important aspect is that both intermediates are related by simply the elimination of $\mathrm{a} \mathrm{Cl}^{-}$ion and thus will both reach the same ring-closed intermediate (2d) [33].
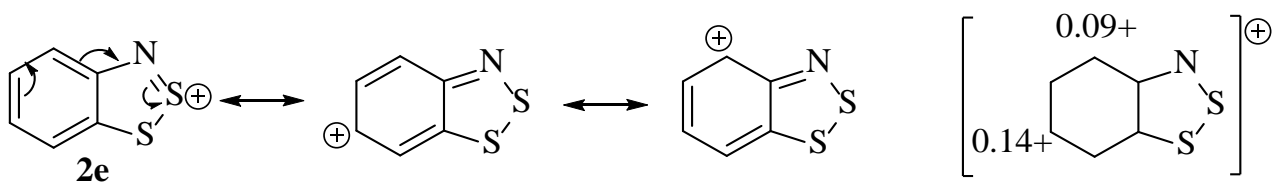

Figure 5. Resonance structures of the benzodithiazolium ion and the computed patrial charges of two carbon atoms in the system [10].

\subsection{Scope of Reaction}

The reaction has been found to work with a wide range of substituted aminophenyls rather than just aniline (1). We have discussed how electron-withdrawing substituents or those with potential leaving group ability (even those that are weak, such as $\mathrm{OH} / \mathrm{OMe}$ ) can be replaced by a chloride ion in nucleophilic substitution, although there are minor mechanistic differences when these groups are present. For groups that cannot behave as a leaving group, such as alkyl groups, the nucleophilic substitution does not happen, and hence, the substituent survives into the product (Scheme 11). Naphthylamines are another suitable substrate, largely forming the dithiazole compounds in higher yields than smaller substituted anilines [16]. There are a handful of instances where the Herz reaction has been applied successfully to other heteroaromatic structures, such as amino-benzothiophenes giving good yields of the dithiazole adducts [34].

Surprisingly, if the substrate is a 2- and 6-substituted (di-ortho) aniline (e.g., 7a or $7 \mathrm{~g}$, Scheme 12), then the Herz reaction still occurs to produce a 1,2,3-dithiazole ring (through an intermediate $N$-thiosulfinylaniline such as $7 \mathbf{b}$ ), although the aromaticity is inevitably not possible, and hence, there are fewer instances where this reaction has been explored $[30,35,36]$. To complicate matters further, Inagaki et al. isolated the benzodiathiazole $3 \mathrm{c}$ as a yellow, crystalline solid in good yield $(70 \%)$, although they also observed that this benzodithiazole form (3c) and the $N$-thiosulfinylaniline $7 \mathbf{b}$ were interchangeable 
in solution [31]. The $N$-thiosulfinylaniline $(7 \mathbf{b})$ was hence not isolated and fully characterised but correlated with existing analytical data to confirm the presence of this moiety (Scheme 12) [37]. This 'equilibrium' was later observed using NMR spectroscopy, finding that while the position was highly solvent dependent, the benzodithiazole was generally the dominant structure and that calculation of the enthalpy and entropy of isomerisation from thiosulfinylaniline to benzodithaizole were both negative values [32]. Coincidentally, the first reported XRD structure of a benzo[1,2,3]dithiazole in the Cambridge structural database (Cambridge Crystallographic Data Centre-CCDC) was this precise tri-tert-butyl compound (7c, Scheme 12, Figure 6a) [25,35]. A similar interconversion phenomenon is observed when one of the ortho-substituents is an ester (e.g., 7g) [38]. These aromaticitydisrupted, $6 \pi$ benzodithiazole structures (such as $7 \mathbf{c}$ and $7 \mathbf{i}$ ) are privileged in that they are readily reduced by thermolysis to form a $7 \pi$ neutral radical, with the loss of the group sharing a ring-position with the sulphur. This will be elaborated in Section 2.6 [4]. Worth noting is that the reactions shown (Scheme 12) were performed in triethylamine/diethyl ether rather than the more popular, mildly-acidic medium of acetic acid. Finally, the reaction can also be conducted if there is a 2-methyl substituent and the 6-position is blocked (with, e.g., a ${ }^{\mathrm{t}} \mathrm{Bu}, 7 \mathrm{~g}$ ), although, in this instance, the resulting $\mathrm{N}$-thiosulfinylaniline intermediate $\mathbf{3 e}$ is a stable product that can be isolated as a solid, rather than forming the benzodithiazole. Its structure has been confirmed by XRD analysis (Figure 6b) [39]. If this ortho-methyl- $\mathrm{N}$-thiosulfinylaniline is heated, an intramolecular reaction occurs with the methyl substituent, giving a benzoisothiazole as the major product, albeit in a quite low yield $(40 \%)$ as a large proportion degrades back to the parent aniline starting material [30].<smiles>[R]c1ccc(N)c(N)c1</smiles>

Scheme 11. The products of the Herz Reaction if 4 substituted anilines are used as the starting material.
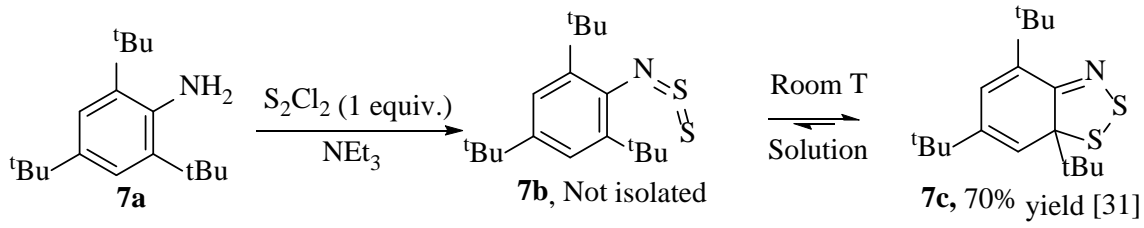<smiles>Cc1[14cH]c(Br)cc(Br)c1N</smiles><smiles>Cc1c(Br)cc(Br)c(N=S=S)c1Br</smiles>

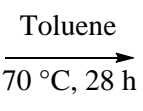<smiles>Brc1cc(Br)c2nscc2c1</smiles><smiles>CN(CCOC(=O)c1cc(Br)cc(Br)c1N)C(=O)O</smiles><smiles>CCOC(=O)c1cc(Br)cc(Br)c1N=C=S</smiles><smiles>CCOC12C=C(Br)C=C(Br)C1=NSC2</smiles>

7i, 73\% yield [38]

Scheme 12. The synthesis of benzodithiazole compounds from an ortho-disubstituted aniline $[30,31,38]$. 


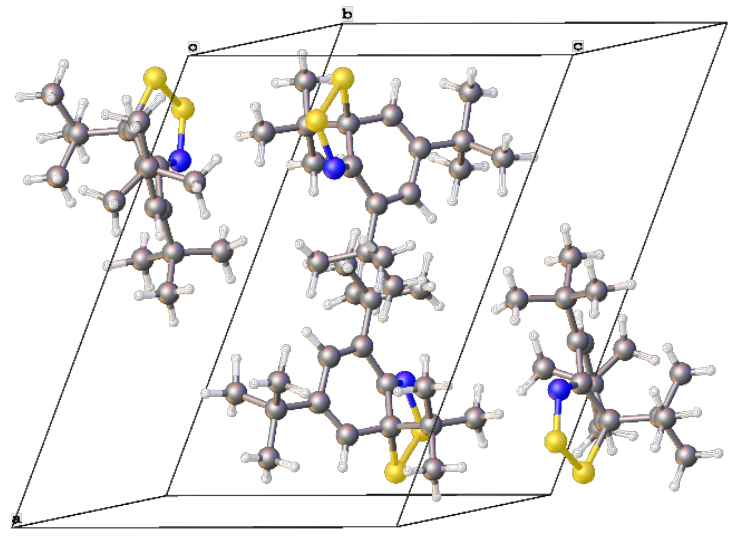

(a)

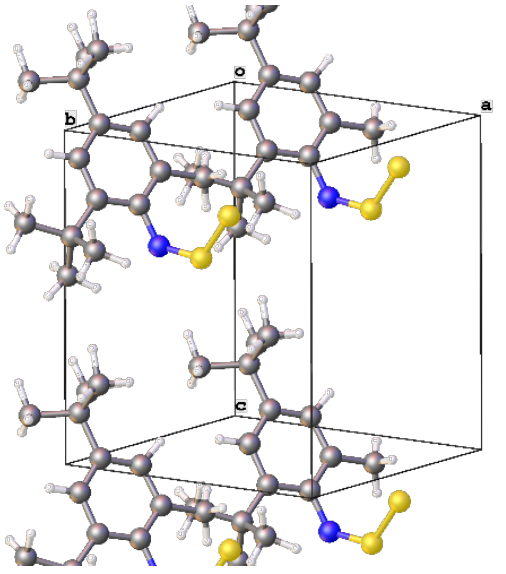

(b)

Figure 6. The unit cells of (a) 2,4,6-tri-t-butyl-7,8,9-dithia-azabicyclo(4.3.0)nona-1(9),2,4-triene (7c) [35] and (b) 2,4-di-t-butyl6-methyl- $N$-thiosulfinyl-aniline (7e) [39].

\subsection{Regioselectivity}

Based upon our proposed mechanism (Scheme 10), the formation of the dithiazole ring involves both electrophilic and nucleophilic ring attacks. The second step is the aromatic $\mathrm{C}-\mathrm{S}$ bond formation, from one of two possible ortho positions of the starting aniline (1, Scheme 10). In asymmetric anilines, it is inevitable that additional ring substituents will often cause the new 5-membered ring to form from one preferential ortho carbon. Specifically, one would expect the most electron-rich of the two carbons to perform this attack and become part of the new ring. In a publication by Van-Snick et al. [14], this effect is evident in the compounds prepared (Scheme 13), although such high levels of regioselectivity in the product formation is somewhat unexpected. The more reactive carbon is probably $\mathrm{C} 2$ because of electron-donating inductive effects from the C3-alykl chain (Scheme 13, 8c). However, C6 is actually similar to C2, so both may therefore be possible, but the paper claims the $\mathrm{C}-\mathrm{S}$ bond always forms at $\mathrm{C} 2$, and the yield is $77 \%$, with no regioisomers reported. There is no explanation as to why the regioselectivity is so high or any record of the other possible product, 8e. Perhaps this other regioisomer was too challenging to isolate or overlooked as a minor product impurity. The compounds were characterised by proton and carbon NMR spectroscopy, along with (accurate) mass spectrometry and IR spectroscopy. Inspecting this data cannot confirm beyond doubt that the proposed regiochemistry is correctly assigned.

Literature scheme

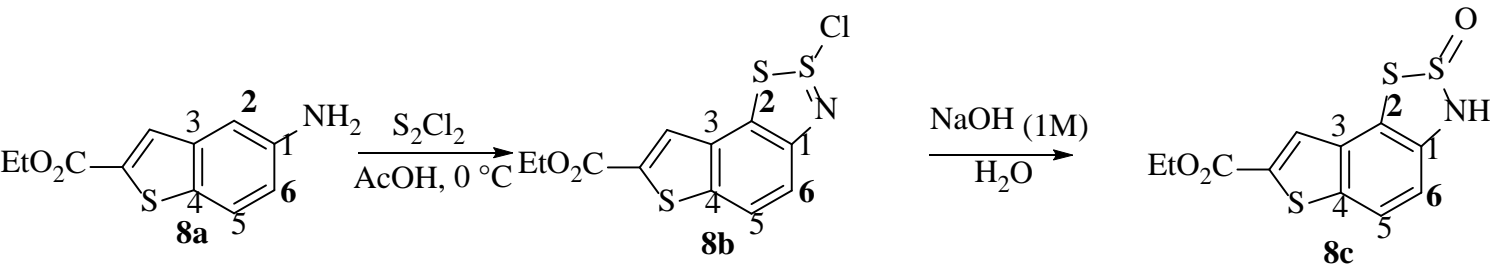

Alternative regioisomer product

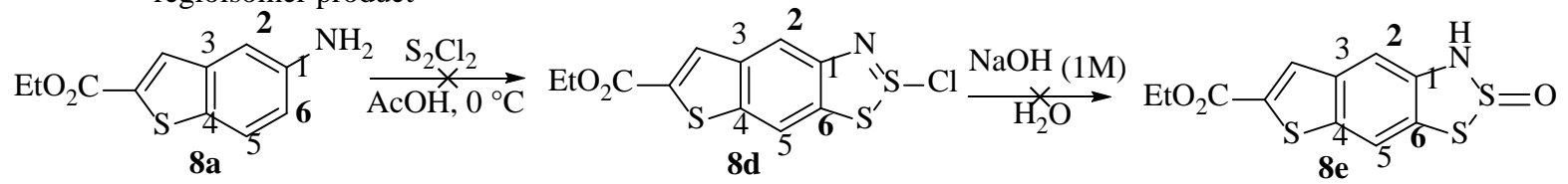

Scheme 13. The literature claim of Van-Snick et al. [14], followed by what would be expected from a general understanding of the theory. 
In contrast, the results obtained by Koutentis et al. [40] on substrate 9a instead gave two distinct Herz salts under similar reaction conditions, in a ratio of approximately 2:1 (Scheme 14). The major product is somewhat surprising given the results from Van-Snick, as the carbon that reacts is less activated by the substituents than in the minor product (though the major product could be marginally favoured sterically). The products $\mathbf{9 b}$ and 9c (Scheme 14) were not separable but were characterised (from the mixture) and distinguished by proton and carbon NMR spectroscopy, as well as mass spectrometry.<smiles></smiles>

Scheme 14. The scheme showing the product distribution obtained by Koutentis et al. [40].

\subsection{Formation of Benzo[1,2,3]dithiazole 'Herz' Radicals}

By the final quarter of last century, it might have appeared that research into Herz's reaction and the properties of benzodithiazole products had been fully exploited; this declining interest was rapidly reversed when it was discovered by the German chemist R. Mayer and co-workers that these structures were capable of forming stable radical anions [41]. Following advancements in Electrospray resonance spectroscopy, the new radical species was identified. This discovery was confirmed by Inagaki et al. when heating benzodithiazole structures in degassed benzene and recording a persistent signal, suggesting the existence of a radicalised structure [30]. (Roland's publications are not listed as references by Inagaki, so it is possible these two discoveries came about independently). The 'Herz radical' of the benzene and naphthalene derivatives were then isolated in a solution by Fabian et al. [42], being described as a red and green solution, respectively.

The generation of the benzodithiazolium 'Herz salts' and subsequent interconversions discussed are thought to largely involve heterolytic processes, though it is the formation of 'Herz radicals' that mainly contribute to many of the unique electronic properties and resulting appearances of benzodithiazole structures in the literature. Mayer continued his investigations well into the 1980s, patenting a large number of new radical structures (>50 structures in total) with their measured g values (all between 2.006 and 2.010) [43].

The most general method to form the Herz radical is to perform a mild reduction of the Herz salt (e.g., 2) with, for example, zinc dust in a non-polar solvent, such as hexane [42], although with the presence of particular ring substituents, the reduction can also be achieved electrochemically [44] or even thermally [41,45] (Scheme 15). The radical formation is accompanied by the Herz salt dissolving (becoming much more soluble) and a prominent colour change, with the radical being separated from any remaining Herz salt by the insolubility of the precursor salts in non-polar solvents. The Herz radicals have very distinctive UV/visible absorption spectra, which, along with their solubility properties, sets them apart from the Herz salts [33,42]. Herz salts (e.g., 2) can be regenerated from the radicals by relatively mild oxidation with, for example, $\mathrm{Cl}_{2}$, or coincidentally, disulfur dichloride [33]. The Herz S-oxides (e.g., 3) are also suitable substrates, with a report of a compound forming a Herz radical intermediate after heating at $80^{\circ} \mathrm{C}$ [37]. This latter species holds interest for potential molecular oxygen-based oxidation sequences, which may be of interest in the formation of reactive oxygen species (ROS) for applications in disinfection and therapeutic treatments [46]. 


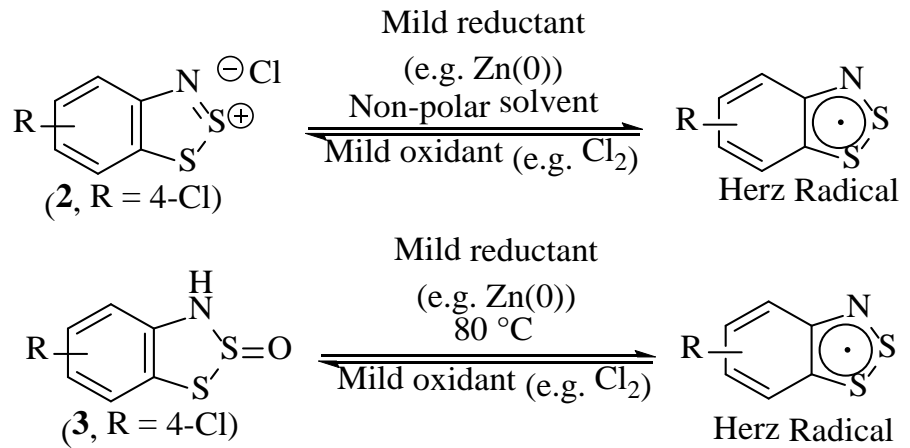

Electrochemical example [44]

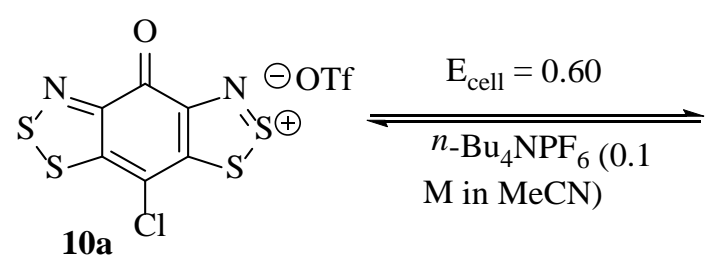<smiles>O=c1c2nssc-2c(Cl)c2c1S[N-]S2</smiles>

Scheme 15. The formation of Herz radicals from Herz salts (e.g., 2) or neutral benzodithiazole-2sulfoxides (e.g., 3) and an electrochemical example [4,44].

Benzodithiazoles, where the aromaticity has been disrupted, are particularly easy to reduce to the radical anion. Such compounds, if trapped in a $6 \pi$ configuration, can be reduced to the corresponding $7 \pi$ radical anions and then again oxidised to the (in some cases, fully-aromatic) Herz salt using $\mathrm{Cl}_{2}$ [4]. A malononitrile moiety has been introduced to a Herz salt with ease, and this can be further elaborated (see Section 3.5). This dramatically activates the ability of the system to accept an electron, to the point where the first electron affinity energy was measured as 2.69 electron volts for the entity (11a) shown (Scheme 16) $[47,48]$. This positive value indicates the compound, 11a, forms a radical anion (11b) that is more thermodynamically stable than the original neutral molecule (11a); not uncommon for various benzodithiazoles, but this value is notably high. The 6-malonitrile-substituted structure is readily reduced both electrochemically or by a chemical mixture of bis(toluene)chromium(0) and tetrakis(dimethylamino)ethylene in a DMF solution. Subsequent studies have further increased the electron affinity with the incorporation of additional moieties, and these new structures have found valuable uses in many applications in materials chemistry (see Section 5) [45].

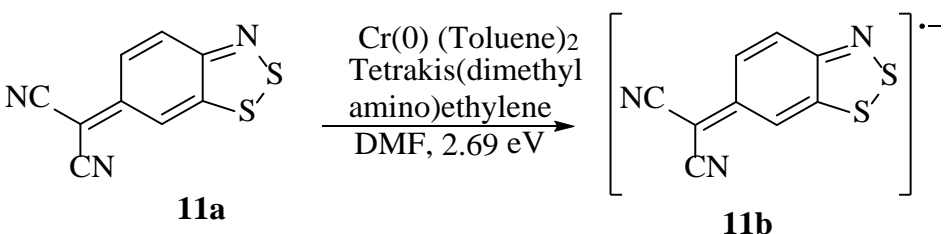

Scheme 16. The reduction of 6-malonitrile-substituted benzodithiazole to the radical anion [47,48].

\subsection{Reactions with Multi-Fuctional Anilines}

Such reactions have presented several challenges and produced inconsistencies in the outcomes when more than one aromatic-primary-amine is present in the starting material. The main issue is that the formation of one dithiazole ring likely deactivates the system to an additional $S_{E} A r$ process. One of the earlier attempts to circumvent this was with 1,5-diaminonaphthalene [49], but the actual product isolated $\mathbf{1 2} \mathbf{b}$ was not the predicted compound 12c (Scheme 17). Instead, the proposed structure $\mathbf{1 2 b}$ was determined supported by the infrared spectra suggesting the presence of the thiosulfinic amide. Quantitative oxidation and sulphur removal by thermolysis or reaction with $\mathrm{NaNO}_{3}$ or $\mathrm{Zn}$ metal suggested that there was only one thiosulfinic amide group per molecule. However, these 
results alone do not conclusively prove the suggested structure $\mathbf{1 2 b}$. It is interesting that the 5-membered dithiazole ring does not form as is known to happen with other naphthyl monoamines [16].<smiles></smiles><smiles>[AsH2][AsH2]</smiles><smiles>S=S1Nc2ccc3c(c2)S(=S)N=C31</smiles>

$12 \mathbf{b}$<smiles></smiles>

12c

Scheme 17. The product $\mathbf{1 2 b}$ obtained by Ried et al., alongside the dithiazoyl product that was not detected 12c [49].

In contrast to this example, a variety of aromatic compounds possessing two dithiazole moieties have been synthesised and characterised, although these have not been generated using the standard Herz reaction conditions [11,15]. Remarkably, there is an account of three[1,2,5]thiadiazole rings bound to benzene (13a, Figure 7) [50,51], as well as the related $[1,2,3]$ thiadiazole (13b, Figure 7) [52]. There remains no evidence of this achievement for the benzotris[1,2,3]dithiazole equivalent (13c, Figure 7).<smiles></smiles>

$13 \mathbf{a}$<smiles></smiles>

$13 b$<smiles></smiles>

$13 c$

Figure 7. The structures of (13a) benzotris[1,2,5]thiadiazole [51], (13b) benzotris[1,2,3]thiadiazole [52] and $(\mathbf{1 3 c})$ benzotris $[1,2,3]$ dithiazolium, for which no structure bearing these three rings is known to exist.

The presence of multiple instances of this moiety increases the reduction potential and makes these derivatives especially attractive in materials chemistry [48]. The first example of a benzo-bis[1,2,3]dithiazole (14b-d, Scheme 18) was prepared by Barclay et al. [15] by reacting diaminobenzenedithiol dihydrochloride (14a) in refluxing sulphur monochloride (having failed to form the target material starting with benzene-1,4-diamine). The solid compound isolated was radical cation $\mathbf{1 4 b}$, which can be either reduced to the neutral compound (14c) with triphenylantimony or further oxidised to the non-radical di-cation (14d) with either sulfuryl chloride or iodobenzene dichloride, but not milder oxidants such as $\mathrm{Cl}_{2}$ (Scheme 18) [15].

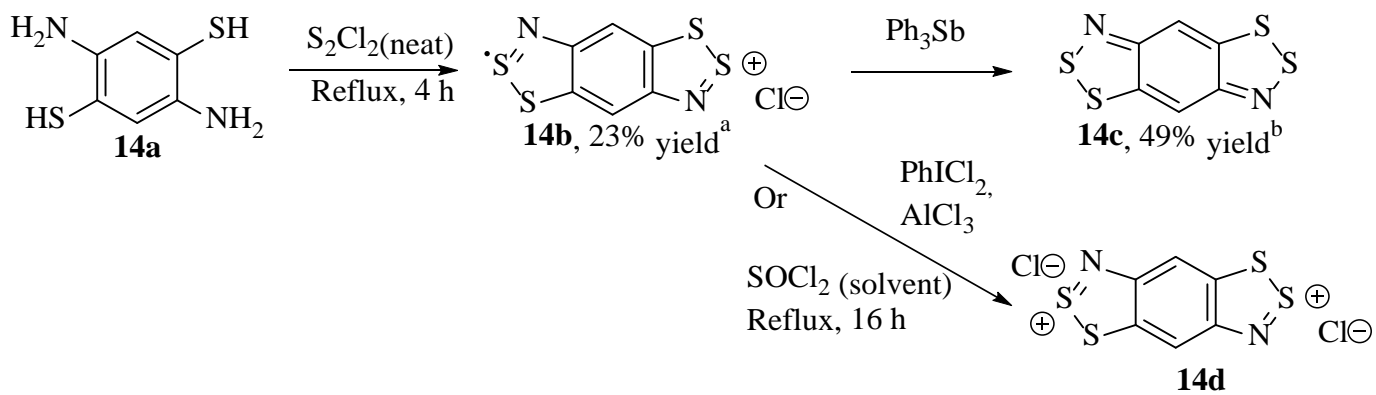

Scheme 18. The results obtained by Barclay et al. in preparing benzo-bis[1,2,3]dithiazole compounds [15]. 
While diaminobenzenes often do not react directly with disulfur dichloride to form the desired benzobisdithiazole, there are some notable exceptions, one being where diaminonaphthalene (15a) was reacted under the Herz reaction conditions to give the desired naphthalene-bis[1,2,3]dithiazole (15b, Scheme 19) [53]. Another exception comes from more recent literature where 2,6-diamino-1,4-dihydroxybenzene was reacted to a benzobisdithiazole product (15d, Scheme 19) [54] as had been demonstrated for a similar compound once before [55]. In these cases, the starting diamine (15a or 15c) was extremely electron-rich (and significantly more so than would be expected for an aryl-diamine), which might explain the success.<smiles>Nc1ccc2cc(N)ccc2c1</smiles>

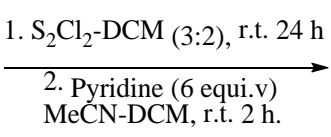<smiles>Nc1cc(O)cc(N)c1O</smiles>

$\mathrm{S}_{2} \mathrm{Cl}_{2}$ (9 equiv.), $\mathrm{MeCN}$, 'gentle reflux' $16 \mathrm{~h}$
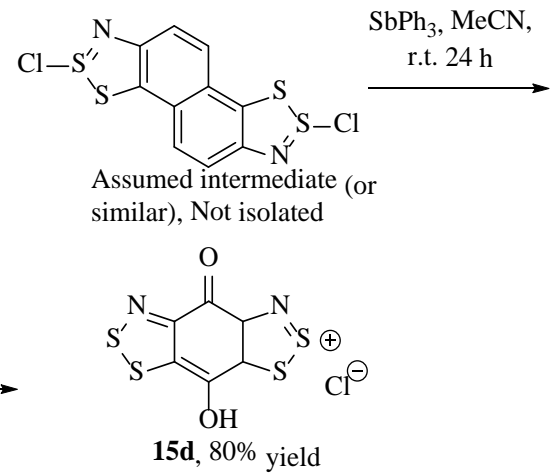

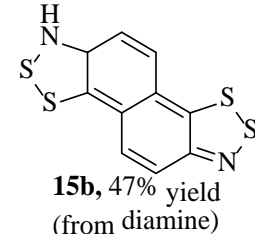

(from diamine)

Scheme 19. Two unique circumstances where two benzodithiazole moieties (15b or $\mathbf{1 5 d})$ have formed from an aryl diamine (15a or 15c) using disulfur dichloride [53,54].

\section{Applications of Benzodithiazoles as Synthetic Intermediates}

The uses of the Herz reaction products, from their age of discovery until today, can be divided into two categories: as synthetic intermediates towards valued cyclic structures (via heterolytic or homolytic transformations) and for their electronic/absorbance properties, previously as dyes and now in smart electronic materials. This section will focus on the derivatives of benzodithiazole compounds, which can be generated through heterolytic mechanisms, while the following section will elaborate on the access to products possible via radical-based transformations. Our final sub-section that is more forward looking will overview their applications in modern materials chemistry.

There are outlined in the literature a variety of simple transformations of Herz compounds to other entities. Overviewed in this section will be their advantages and disadvantages when applied to laboratory or commercial-scale projects. The Herz reaction itself is easy to perform in the laboratory by adding liquid disulfur dichloride dropwise to a stirred solution of aniline in acetic acid solvent (Scheme 20). Following filtration and washing of the generated precipitate with organic solvents, the product salt is collected, and although it has been separated from organic by-products, such as chloroanilines, significant contamination of elemental sulphur is typically also collected. While some clearly very toxic reagents are employed, and measures are needed to mitigate the $\mathrm{HCl}$ fumes that are generated. The reaction uses mild conditions, sustainable solvents and very affordable reagents (disulfur dichloride, CAS 10025-67-9, Aldrich price dated May 2021; $1 \mathrm{~kg} £ 34.80$ ). Literature yields range from low, 30\% to much higher, $80 \%$, as vastly different synthesis methods and purifications are used. In some cases, it is possible the reported yield includes some contamination by elemental sulphur (which could go undetected by general methods of NMR spectroscopy and MS). Overall, the yield is non-quantitative because of side processes that produce compounds such as 4-chloroaniline, azobenzenes and sulphur-phenyl-diimides [4,33,37], although these are readily removed from the product by washing with a non-polar solvent such as toluene (as the Herz salt is insoluble). The Herz chloride salt itself remains very difficult to purify further, and this is generally achieved by performing an ion exchange with the installation of a larger counter-anion to form a salt with greater solubility, followed by recrystallisation [4]. 


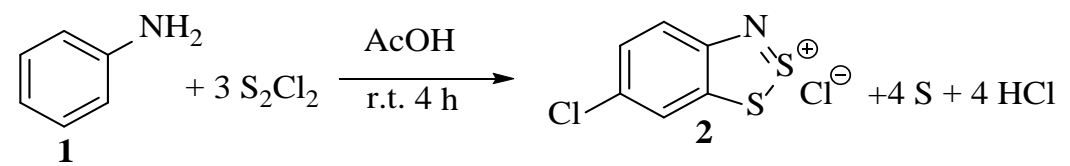

Scheme 20. The very general procedure for the first stage of the Herz reaction.

While well-suited for a small-scale preparation, limitations regarding process chemistry include the super-stoichiometric amount of disulfur dichloride that is often used (5 or more equivalents), along with the seemingly inevitable chlorination of the para carbon relative to the amino group (see Scheme 10). This is without considering the problematic disposal of the cocktail of chloro-aromatic compounds (several being classed as persistent organic pollutants-POPs) that are found in the filtrate when filtering the Herz salts from the reaction mixture and washing. Thus, due to the low characteristic yields and problematic purification, designing routes for commercial application would be challenging, even if the starting materials are very affordable. Furthermore, the reactions are somewhat exothermic with disulfur dichloride, although not to the extent of being a cause for concern if properly managed, and could be readily controlled, for example, in a continuous flow system [56]. However, to date, the application of the Herz reaction for bulk chemical production remains a major challenge, especially with regards to purification, which undoubtedly restricts the utilisation of these privileged chemical entities.

\subsection{Synthesis of Aminothiophenols}

One of the simplest transformations of the Herz product is in the preparation of 2-aminothiophenol compounds (e.g., 3d, Scheme 21). Consequently, this approach was further patented [57] by Herz within a year of the original 'Herz reaction' patent [18].
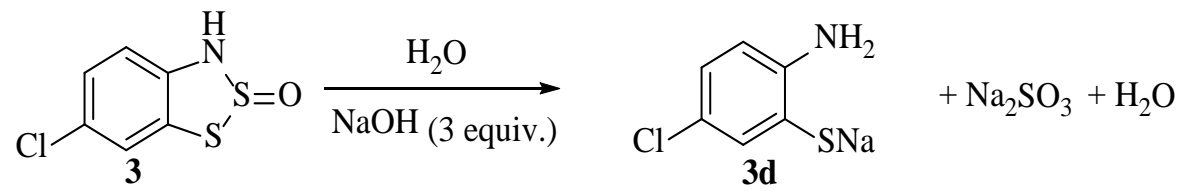

Scheme 21. The ring-opening of neutral Herz compounds to form the respective 2-aminothiophenols.

This hydrolysis (Scheme 21) also appears in several later publications, and while the conditions may not have been optimised or fully investigated, the process was favoured at the time as a means to rapidly synthesise 2-aminothiophenols on moderate scales for other projects [19]. The procedure works best when applied towards ortho aminonaphthalenethiols, as the selectivity and isolated yields are seemingly higher [13,16,58,59]. Yields as high as $84 \%$ for the benzodithiazole formation and $90 \%$ for the final hydrolysis have been reported at a moderate (70 g) scale of 2-aminonaphthalene-1-thiol [60]. Today, aminothiophenols are generally available and affordable to buy for small-to-medium-scale laboratory projects [61]. However, from a process perspective, they are still valued targets. Often released from benzothiazole derivatives by hydrolysis, the source is atom inefficient, and the removal of the $\mathrm{C} 2$ carbon requires a lot of energy, so there is an opportunity for improvement [62,63]. An alternative legacy method is using the Zinin reduction of 2-nitrochlorobenzene [64-67], although the reported yields for this process are generally modest at best, and there appears to have been little investigation into this process in recent times. While the formation of the ring-opened aminothiophenol from the benzodithiazole (Scheme 21) is also incredibly simple, it is also the limitations of average yields and product contamination with, e.g., sulphur residues that are problematic.

\subsection{Formation of Benzothiazoles}

There are two interesting reports of reacting the benzodithiazole products of the Herz reaction to make benzothiazoles while avoiding the final ring-opening step with sodium hydroxide (as a segregated step) $[13,21]$. The first originates from Sawhney et al., 
where the hydrolysed Herz salt is reacted with either benzoyl chloride, benzaldehyde or even benzoic acid in a mildly basic medium. The phenyl-substituted products shown $(\mathbf{1 6 a}-\mathbf{d}$, Table 1) were synthesised. The mechanism for the ring-opening of the intermediate dithiazole S-oxide to form the final products could either be due to high-temperature hydrolysis or potentially a cheletropic cyclo-elimination process. The two intermediates will have different oxidation levels depending on whether the reagent is the aldehyde or the acid/acid chloride, but the reaction conditions are capable of facilitating an autooxidation regarding the aldehyde (in fact, the yields were often higher when using the aldehyde). The scope of the process was tested only on 2-phenyl-substituted benzothiazoles, although we ourselves have experimentally found the scope to also include 2-unsubstituted benzothiazoles [68]. Finally, as for all Herz processes, the product will have an additional aromatic chloro group present, which might require removal.

Table 1. The synthesis of 2-phenylbenzothiazoles by the Herz reaction [21].

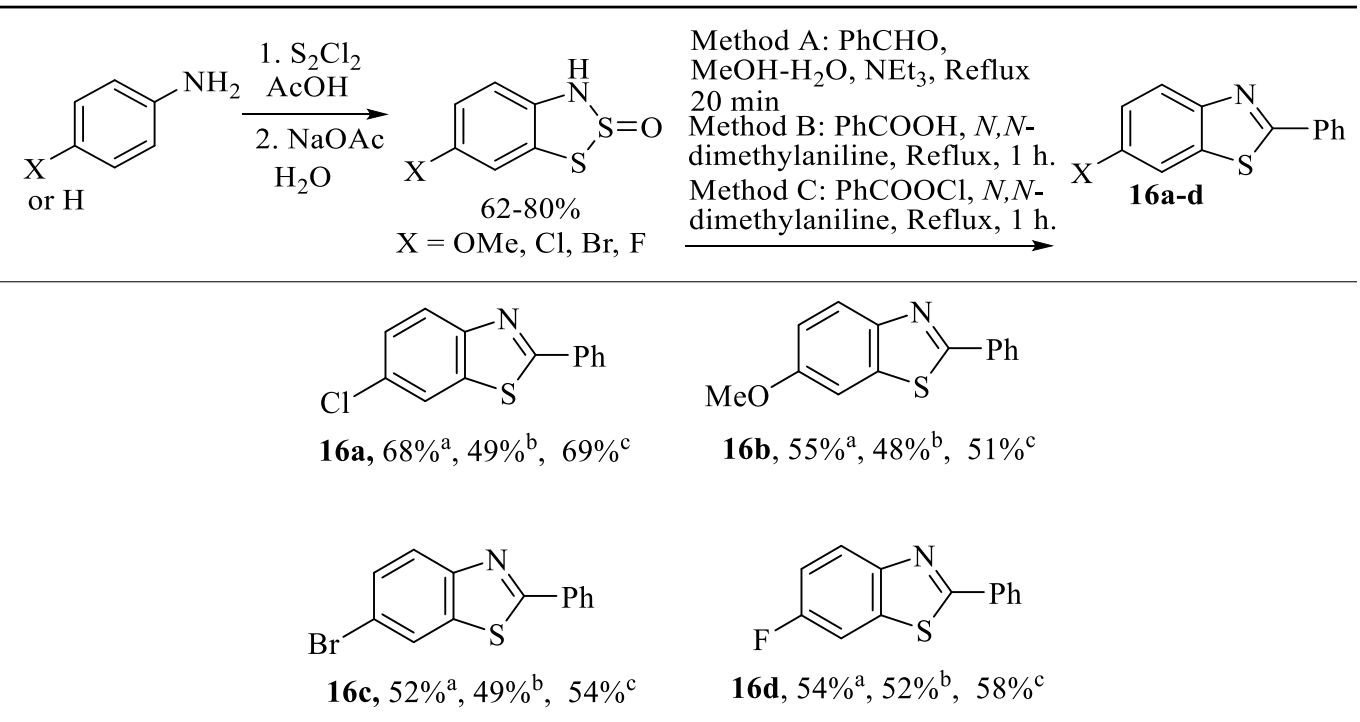

a Synthesised from 'method A'. ${ }^{b}$ Synthesised from 'method B'. ${ }^{c}$ Synthesised from 'method C'. Percentages refer to pure isolated yields.

\subsection{Formation of Secondary 2-Aminobenzothiazoles}

Specific 2-amine-substituted benzothiazoles can be generated by the reaction of the intermediate dithiazole S-oxide compound with isocyanides (Table 2) [13]. These entities are incredibly valued in the discovery of new APIs but are often non-trivial to synthesise. As such, an optimised reaction sequence would be invaluable to both a medicinal hit-to-lead process and the scaled preparation, offering advantages over similar preparations [69,70]. In total, fourteen different benzothiazole-secondary amines (18a-n) have been generated from five different benzo-1,2,3-dithiazole 2-oxides (17a-e, Table 2); the yield varied widely, with some being as low as $8 \%$, though there is no indication that the process was optimised. This publication appears to be the first consideration of reacting Herz salts with a nucleophile (other than water) at the 2-position. The mechanism uses an iodine catalyst to activate the dithiazole ring so that the isocyanide can insert into the weak S-S bond. However, the precise function of the $I_{2}$ was not fully elucidated. When heating was performed employing microwave radiation in the experiments [13], the rate of formation was faster, but the yield decreased. The substrate range remains good and demonstrates the possibility of installing a library of amine functionalities (derived from readily available commercial isocyanides). As an aside, the reported yields for two of the Herz compounds were surprisingly high. However, the characterisation data provided does not confirm that these samples are free of contamination from elemental sulphur, which may also impact the yield in the subsequent derivation reaction. The moderate-to-high yields for some of the final compounds are particularly encouraging, considering the Herz compound intermediates are collected 
by filtration and then reacted crude without any purification. It is likely that further optimisations could enhance the final yields. In addition, from a scale-up perspective, all of the reagents used are affordable, and with the exception of the disulfur dichloride, are employed in minimum/catalytic quantities (the ratio of Herz compound to isocyanide reagent is $1: 1$ ). For this publication, the compounds were isolated by chromatography, although recrystallisation is likely to be an efficient purification method at larger scales, given the established behaviour of these larger benzothiazoyl-amines [71-73].

Alternatively, it should be noted that these simple entities could instead be synthesised by reacting the primary 2-aminobenzothiazole derivative with an electrophilic reagent or an aromatic cross-coupling. However, for targets where these methods are not suitable, this reaction does offer access to these valued targets in two relatively simple chemical steps (isocyanide formation, then substitution with Herz compound). The issue surrounding para chlorination is surprisingly resolved by the coincidence that many such APIs include an existing substituent at this position (often to increase lipophilicity and solubility).

\subsection{Formation of 2-Mercaptobenzothiazoles}

There are a few reports of the 1,2,3-dithiazole compounds reacting with carbon disulphide to form 2-mercaptobenzothiazoles (Scheme 22) [74,75]. The reason for the rarity of such transformation reports might be that these structures are readily available from the industrial process: heating aniline with sulphur and carbon disulphide at high temperatures [68]. This alternative reaction of the Herz compound (Scheme 22) is unlikely to compete with such a well-established process, although the reported yield is very high considering the product was 'recrystallised twice' [75].<smiles>O=S1Nc2ccc(-c3ccccc3)cc2S1</smiles>

Scheme 22. A single reported reaction of a Herz compound forming a 2-mercaptobenzothiazole [75].

Table 2. The synthesis of 2-aminobenzothiazoles from Herz compounds (e.g., 9) [13].

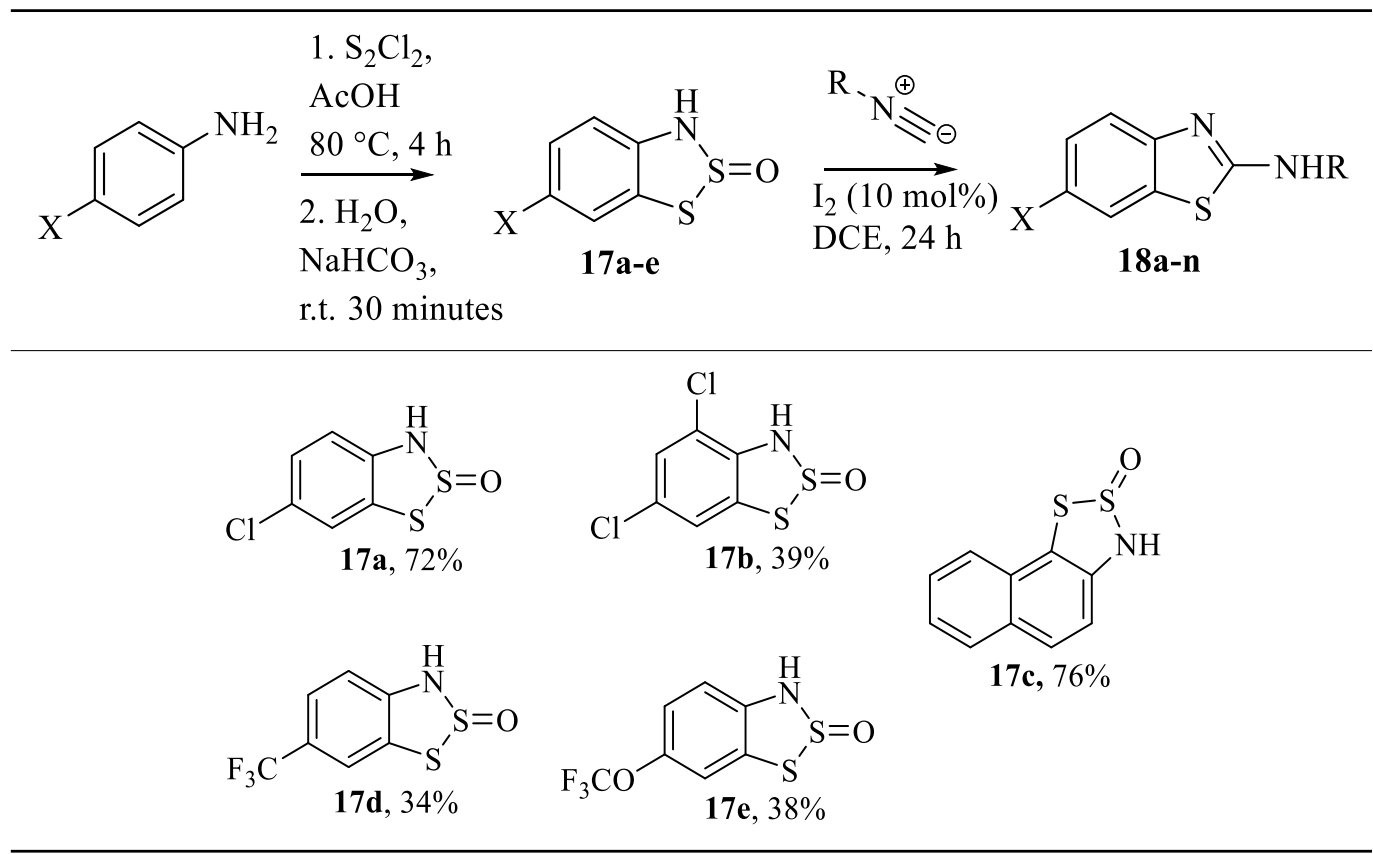


Table 2. Cont.

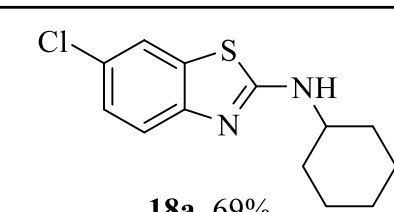

18a, $69 \%$<smiles>Cc1cccc(C)c1Nc1nc2ccc(Cl)cc2s1</smiles>

18d, 49\%<smiles>COc1ccc2nc(NC3CCCCC3)sc2c1</smiles>

18g, $58 \%$<smiles>CC(C)(C)Nc1nc2ccc(C(F)(F)F)cc2s1</smiles>

18j, $52 \%$<smiles>CC(C)(C)Nc1nc2ccc3ccccc3c2s1</smiles>

18m, $40 \%$<smiles>CC(C)(C)Nc1nc2ccc(Cl)cc2s1</smiles>

18b, $47 \%$<smiles>Clc1cc(Cl)c2nc(NC3CCCCC3)sc2c1</smiles>

18e, $34 \%$<smiles>COc1ccc2nc(NC(C)(C)C)sc2c1</smiles>

18h, 57\%<smiles>Cc1cccc(C)c1Nc1nc2ccc(C(F)(F)F)cc2s1</smiles>

18k, $78 \%$<smiles>Cc1cccc(C)c1Nc1nc2ccc3ccccc3c2s1</smiles>

18n, 79\%<smiles>Clc1ccc2nc(NCc3ccccc3)sc2c1</smiles>

$18 \mathrm{c}, 55 \%$<smiles>CC(C)(C)Nc1nc2c(Cl)cc(Cl)cc2s1</smiles>

18f, $26 \%$<smiles>FC(F)(F)c1ccc2nc(NC3CCCCC3)sc2c1</smiles><smiles>c1ccc2c(c1)ccc1nc(NC3CCCCC3)sc12</smiles>

181, 54\%

Percentages refer to pure isolated yields.

\subsection{Nucleophilic Aromatic Substitution}

Anilines (including the ring-open 2-aminothiophenol) are electron-rich aromatic systems; the $\pi$-donor effects from the amine make them perfect for electrophilic aromatic substitution but normally are inert to nucleophilic attack. Noting that some substituents to the ring were replaced by chloride during the Herz reaction, Herz proposed the possibility that the same could be done with other nucleophiles. A range of aromatic amines was reported to react with the Herz thiazolium salts (e.g., 2), displacing the chloride introduced during the Herz reaction to form a biaryl aniline product (Scheme 23) [76]. The extent to which the dithiazolium moiety activates the opposite $\mathrm{C}-\mathrm{Cl}$ bond to substitution is remarkable, as the scope includes arylamines (which can be poor nucleophiles) to displace the chloride [77]. However, more surprising, Herz salts based on the more electron-rich naphthalenes can also undergo nucleophilic substitution [78]. The full experimental details and product yields are not easily realised from the patent literature; however, the reaction is described as occurring at ambient temperature, requiring two equivalents of the aniline (one as nucleophile, the other as a base) and taking a 'very long time' to complete. The reactions were performed in a medium of acetic acid, and the products were isolated by 
filtration and, in many cases, were crystalline. Interestingly, this makes it comparable to the general conditions used in the Herz reaction (e.g., Scheme 20), and hence, such substitution could probably occur as a side-process. However, the shorter reaction time and the excess of sulphur monochloride used in the Herz reaction likely favour complete consumption of aniline to the thiadiazolium rather than the insertion of the aniline into the product. As noted, the specific identities of the compounds made and their yields are not reported numerically, instead of being described as 'good.' The products were derivatised to the ring-opened aminothiophenols (as per previous instances where proof of structure was not possible on the original products) to aid with the characterisation of structures.<smiles></smiles>

$\mathrm{R}=\mathrm{H}, \mathrm{Me}$, naphthyl

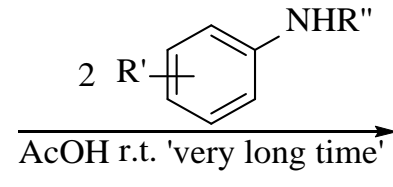

$\mathrm{R}^{\prime}=\mathrm{H}, \mathrm{Me}, \mathrm{OH}, 3-\mathrm{NO}_{2}$ napthyl, anthraquinone, etc.<smiles></smiles>

Yields not reported $\mathrm{R} "=\mathrm{H}$, alkyl, aryl

Scheme 23. The reported scheme for the displacement of the 6-chloro of Herz salts with a primary arylamine [76].

This substitution process was later confirmed by Strelets et al., who also discovered that the 4-methoxy substituent could also function as a leaving group in displacement reactions, albeit at one-eighth of the rate of the chloride (Scheme 24) [78]. This is noteworthy because, while OMe is an acceptable leaving group, it is such an effective $\pi$-donor substituent that it typically renders most aromatic systems impervious to any nucleophilic substance. Another interesting finding was that the displacement of one such leaving group with aniline prevented the addition of a second aniline if there were additional leaving groups present. This is consistent with the knowledge that these $\pi$-donor substituents would repel incoming nucleophiles, even more so than the methoxy.<smiles>O=[SH]1(Cl)Nc2ccc(Cl)[Z12]c2S1</smiles>

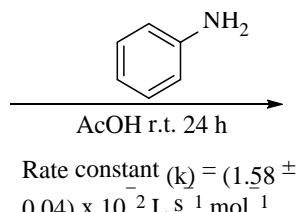

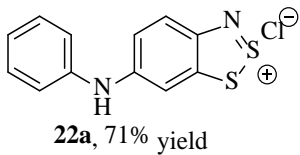<smiles>COc1ccc2c(c1)SS(=O)([O-])=N2</smiles>

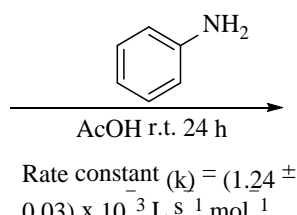

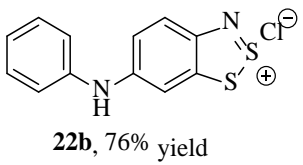

Scheme 24. The measured rate constants, comparing the rate of $S_{N} A r$ of the chloride substituent versus the methoxy in the otherwise equivalent structure [78].

The scope of $\mathrm{S}_{\mathrm{N}}$ Ar reactions with Herz salts was expanded upon by Koutentis et al. [40] and more recently applied in research by Makarov [47] and Chulanova [45]. Although there were some difficulties in the preparations of particular Herz salts, the intermediates that could be isolated in high purity were reacted successfully with malononitrile to form the target adducts in low-to-mid yields (Table 3). In each case, the product was isolated by chromatography, although the reactions were generally unselective and a lot of byproducts were detected in the reaction mixture, including 2-cyanobenzothiazoles, the oxidised 'sulfone' form of the Herz starting materials and even evidence of thiocyanateinsertion into the aromatic system. 
Table 3. The general scheme and isolated malononitrile adduct products from the study by Koutentis [40].

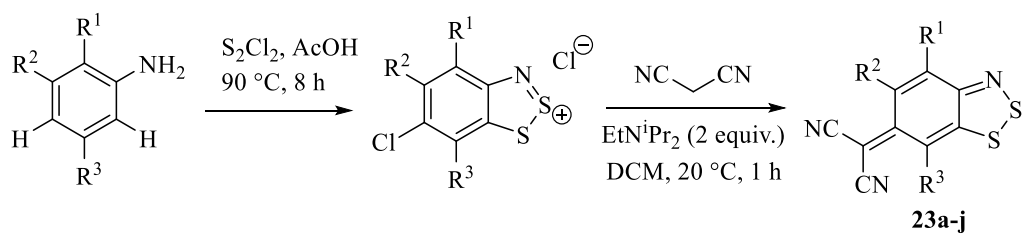<smiles>N#CC(C#N)=c1ccc2c(c1)SSN=2</smiles>

23a, $11 \%$<smiles>Cc1c2c(ccc1=C(C#N)C#N)=NSS2</smiles>

$23 \mathrm{~d},<5 \%{ }^{\mathrm{a}}$<smiles>Cc1cc2c(c([15NH2])c1=C(C#N)C#N)SSN=2</smiles><smiles>Cc1cc(C(C#N)C#N)cc2scnc12</smiles>

23b, $16 \%$<smiles>COc1cc(=C(C#N)C#N)cc2c1=NSS2</smiles><smiles>Cc1cc(=C(C#N)C#N)c([15NH])c2c1=NSS2</smiles><smiles>CC(C#N)=C(C#N)c1cc2snnc2cc1C</smiles><smiles></smiles><smiles></smiles><smiles>N#CC(C#N)=c1cc2c(c3nsnc13)=NSS2</smiles>

Percentages refer to pure isolated compounds.

\subsection{Future Applicablity in Synthesis}

Many publications describing the reaction of Herz 1,2,3-dithiazole compounds to other simple structures are academically noteworthy; however, they are not utilised commercially. The issues outlined simply outweigh any value added to the raw materials, and hence, such small targets are generally made using well-established pathways [77]. To speculate whether the Herz reaction could have possible future applicability, all three of the key transformations (Figure 8) that occur as part of the process must be considered in tandem.<smiles>Nc1cccc(I)c1</smiles>

- Regioselective and protected introduction of 1,2-Nitrogen-Sulphur moiety.

- Regioselective introduction of chloride to para position of aniline as a scaffold for substitution, or otherwise.

- Activation of the structure to $S_{N} A r$.

Figure 8. The three transformations that occur simultaneously in the Herz reaction.

With these three transformations (Figure 8) in mind, there is potential to reach complex API structures (Figure 9) in relatively few steps, from simple anilines. For example, the benzothiazole component of antidepressant 'E2011' could be retro-synthesised from the 1,2,3-dithiazolium and the simple carboxylic acid shown. Additionally, the aromatic chloride introduced in the Herz reaction could act as a scaffold for coupling with the oxazolidinone shown (Figure 9) and the electron-withdrawing dithiazolium ring enabling the nucleophilic attack, adding the left-hand-side functionality with ease. Four further 
examples are proposed, where a complex API is retro-synthesised back to simple building blocks by considering the Herz reaction.

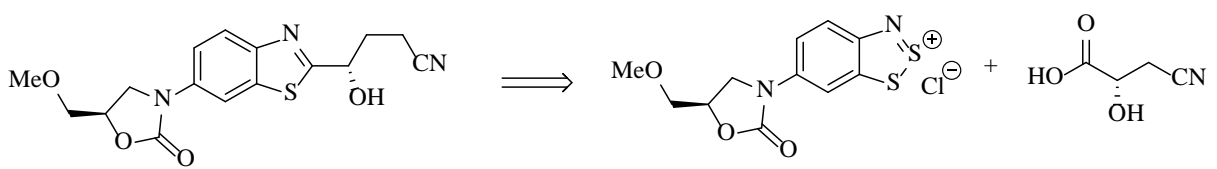

'E2011' Antidepressant, [79] other medicinal [80]
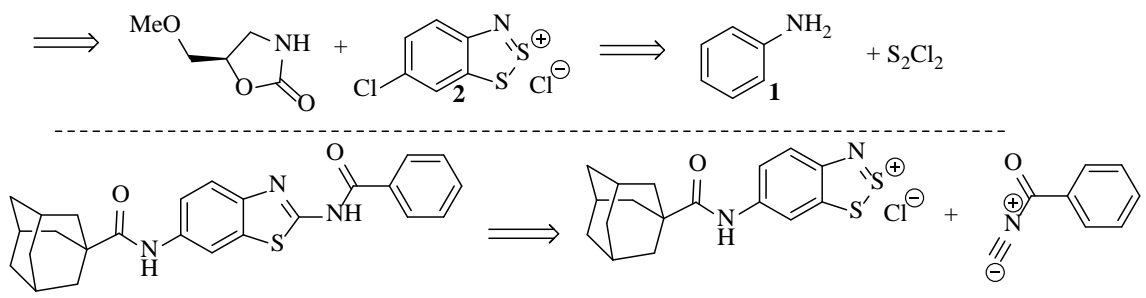

Ceramide Kinase Inhibitor, [81]
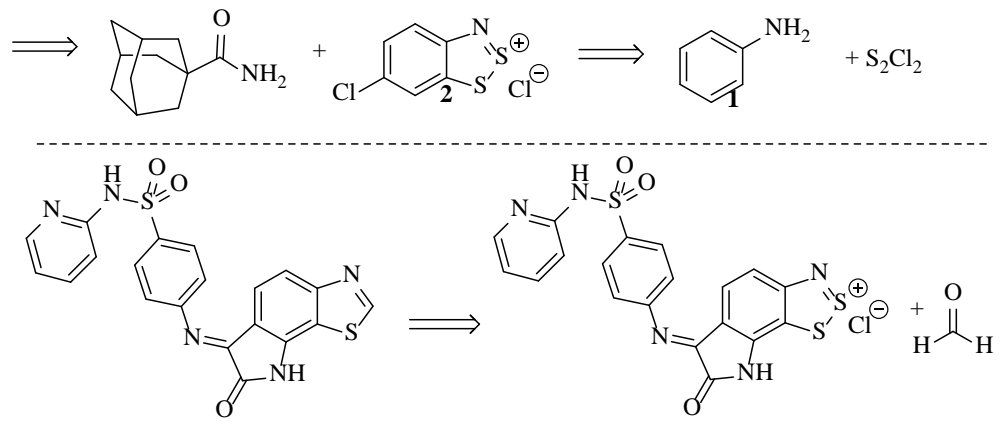

Fibrosis \& other Inflammation Inhibitor, [83]
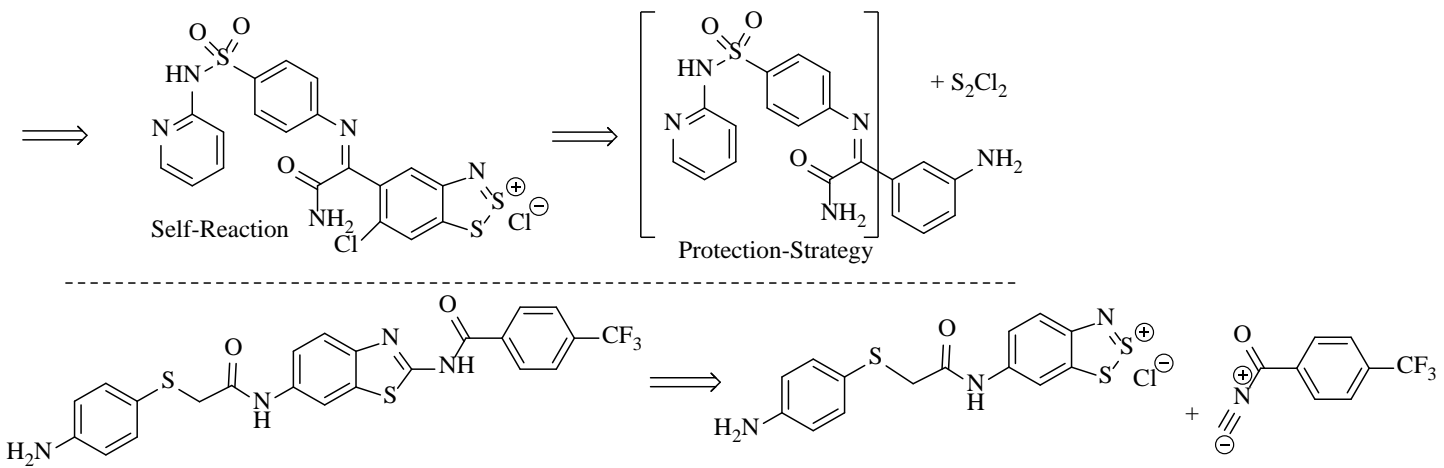

NAE (Nedd8 Activating Enzyme) Inhibitor, [82]
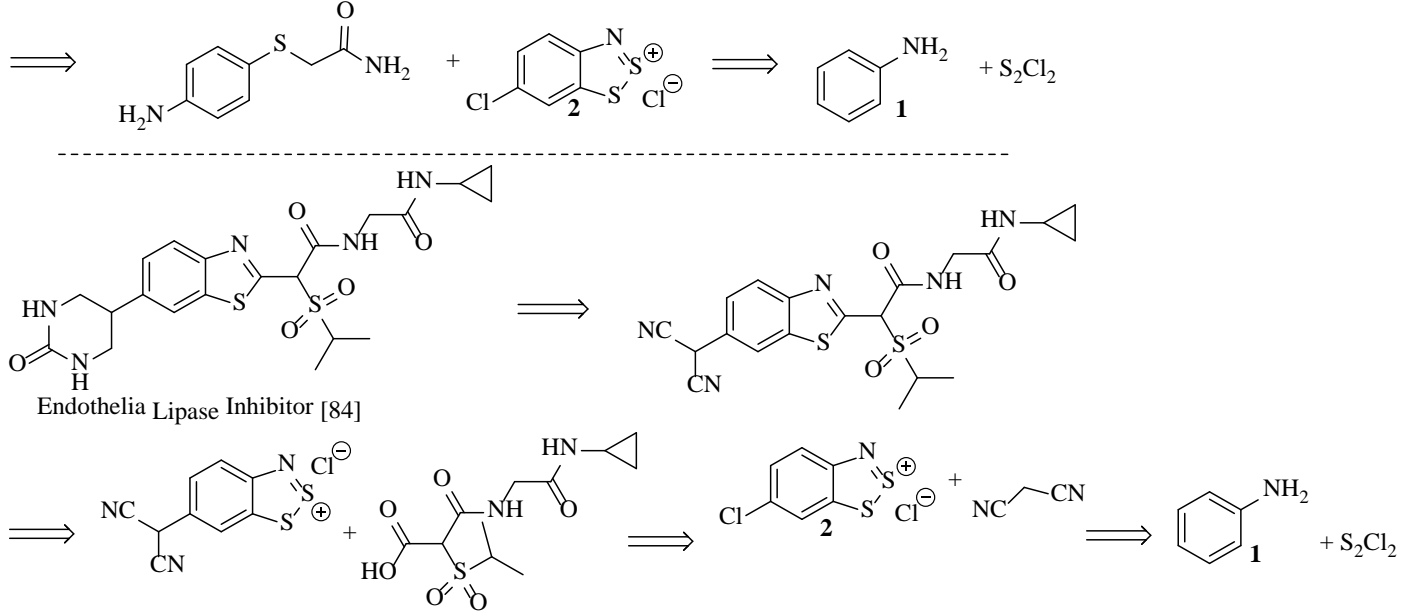

Figure 9. Five different confirmed APIs and their theoretical retro-synthesis using the Herz reaction [79-85]. 


\section{Application of the Herz Radicals as Synthetic Intermediates}

In addition to the scores of materials-based applications, the 'Herz radicals' have found synthetic value as intermediates towards other unique compounds. In comparison to the heterolytic processes outlined in the previous sections, the corresponding homolytic processes have not been as widely investigated, and the isolated yields are not always as high. The benzodithiazoyl radical nonetheless provides entry to some highly novel and complex systems, many with few or no known alternative formation procedures.

\subsection{Reaction with Molecular Oxygen}

It has become known due to stability issues that some Herz radicals could react with molecular $\mathrm{O}_{2}$ to form new products, though this had not been utilised deliberately to try and identify the products until an investigation by Makarov et al. [86]. Interestingly, a disulphide derivative (24c) was isolated in decent yield $(60 \%)$ by reacting the Herz radical shown $(\mathbf{2 4} \mathbf{b}$, Scheme 25$)$ with molecular oxygen in solution. This appears to be a stand-alone example, with no records of similar compounds or derivatives.

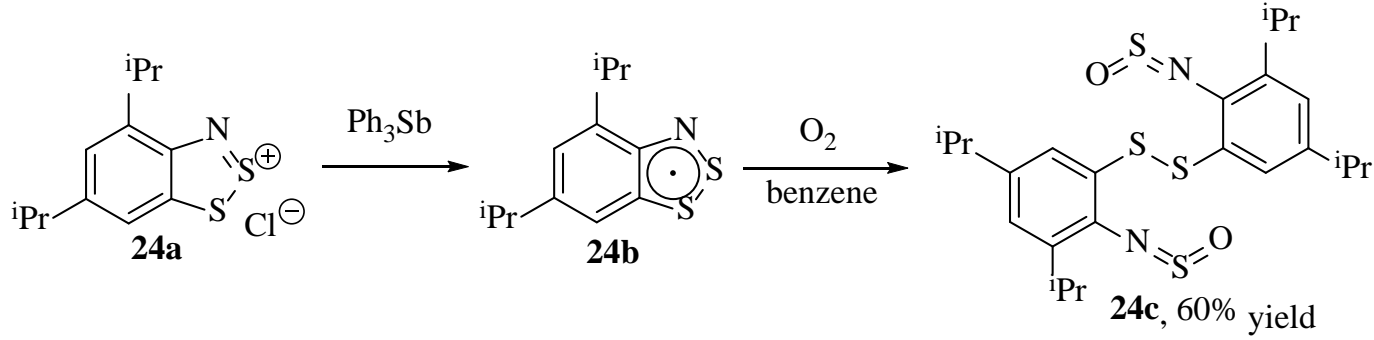

Scheme 25. The synthesis of a new compound identified by Marakov et al. [86].

\subsection{Synthesis of Phenazines}

Phenazines, whose compound class includes high-valued redox-active structures, such as pyocyanin [87], are self-condensation products of the reaction of benzodithiazoyl radicals. These desirable structures have numerous issues in their supply chains [88-90], so alternative syntheses are frequently considered. While the formation of phenazines from radicalised $\mathrm{N}$ - and $S$-containing aromatics was not novel [91], an entirely new method was discovered by Mayer in 1985 when heating the Herz radical generated from $3 H$-naphtho[2,1d][1,2,3]dithiazole 2-oxide (25a, Scheme 26), forming the target phenazine (25d) in high yield [33]. This outstanding transformation was further reasoned mechanistically by Rawson [4], though there are no further experimental reports of its use nor any evidence of an investigation into the substrate scope.

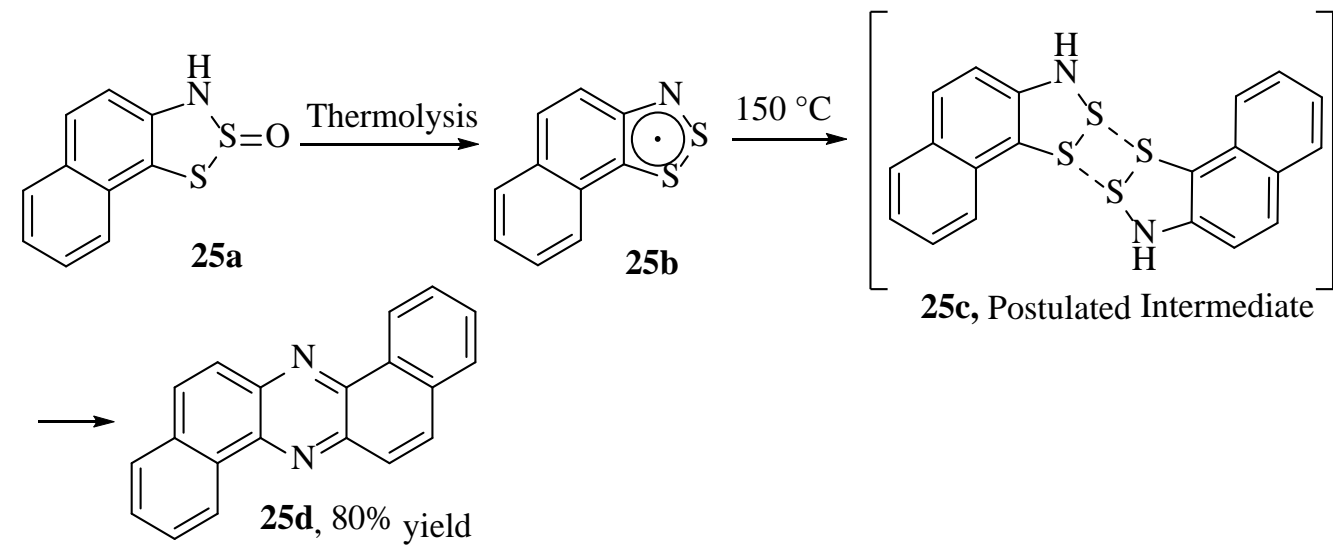

Scheme 26. The formation of dibenzo[a,h]phenazine in high yield from the Herz radical $[4,33]$. 


\subsection{Synthesis of Phenothiazines}

Mayer, Zhivonitko, Marakov and co-workers have reported on the formation of phenothiazines from self-condensation of benzodithiazoyl radicals [50]. Two self-condensation isomer products, each from an intermediate unsubstituted and fluoro-substituted 1,2,3benzodithiazoyl radical (26d), were synthesised [92]. These crystalline compounds were isolated in very low yield from a reaction mixture (for which the 1,2,3-benzodithiazoyl radical $\mathbf{2 6} \mathbf{b}$ was detected as a minor intermediate), but also in higher $(30 \%)$ yield by slowly reacting the fluorinated 2-triphenylphosphoranimine-substituted benzodithiazole (26a) at ambient temperature in chloroform (Scheme 27). It is interesting to speculate on a difference in the isolated product compared to Mayer's process above [33]. It is likely the fluoro substituents, which would substantially reduce the electron density of the ring and render the substrate very reactive to $S_{N} A r$ processes.<smiles>Fc1c(F)c(F)c2sc(N=Pn3c4ccccc4c4ccccc43)nc2c1F</smiles>

26b, Detected intermediate (in solution)

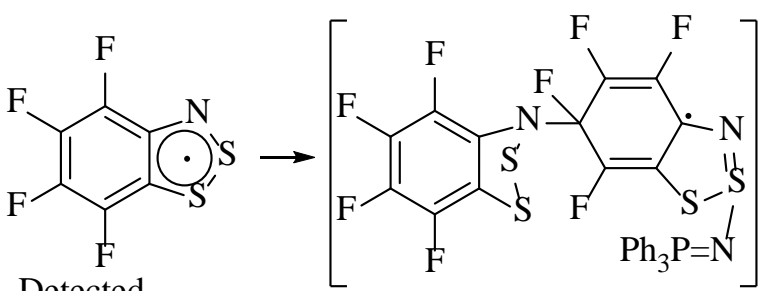

26c, Postulated intermediate<smiles></smiles>

Scheme 27. The synthesis of phenothiazines by self-condensation of benzodithiazoyl radicals [50].

The crystal structures of compound 26d [93] and a related regioisomer [94] (that were both isolated from a process other than depicted in Scheme 27) were deposited to the CCDC, and their respective unit cells are shown (Figure 10). Their perfectly planar configuration allows for uniform $\pi$-stacking in the crystal structure, and their unit cells are cuboidal ( $\alpha=$ $\beta=\gamma=90^{\circ}$ ). Aesthetically pleasing crystal structures aside, these tetracycles are a novel structural moiety, for which no application has yet been idealised [50].

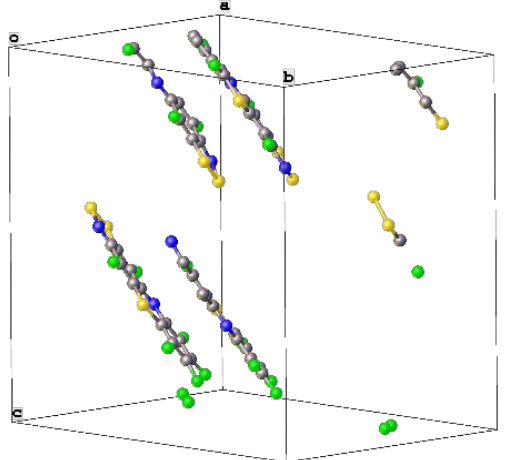

(a)

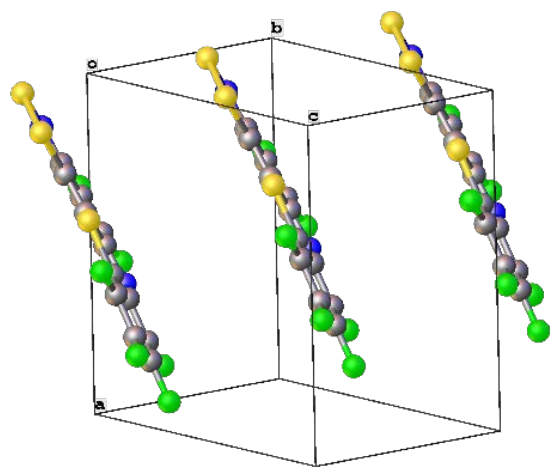

(b)

Figure 10. The unit cells of: (a) 4,6,7,8,9,11-hexafluoro(1,2,3)dithiazolo(5,4-b)phenothiazine (26d) [93] and (b) Related compound 4,5,7,8,9,10-hexafluoro(1,2,3)dithiazolo(4,5-c)phenothiazine, with some molecules outside of the unit cell showing the stacking as the unit cell contained only a single molecule [94]. 
We have already discussed how multiple studies have struggled to isolate any crystalline polymorphs of simpler benzo[1,2,3]dithiazole compounds, such as the parent Herz salt (2) or hydrolysed sulfone product (3) obtained from aniline (1). Indeed, this has been attempted in our own laboratory, although no suitable crystalline material could be generated without exchanging to a large counter-anion [68], as per previous literature suggestions [4]. An interesting consideration is from the degree of $\pi$-stacking and its comparison to that displayed in Figure 10, with the caveat that such stacked-planar structures are possible in only a relatively few circumstances. The benzodithiazolium anion of the Herz salt is a flat, 10- $\pi$ aromatic system but must be supported by a counterion, and hence, any crystal structure is dictated by the ionic interactions as well as $\pi$-stacking. Marakov et al. observed significant $\pi-\pi$ interactions in their covalent iminophosphorane crystals (e.g., 26a, Scheme 27), although as the triphenylphosphine substituent is large, a back-to-back arrangement was adopted, rather than a lattice of flat sheets. Stacked sheets are, however, observed with the aforementioned 8- $\pi$ (non-aromatic) malononitrile-coupled benzodithiazoles (e.g., Table 3) $[17,47]$ as well as some other compounds to be covered in Section 5.3. In summary, using homolytic processes, Herz compounds have been reacted to form unusual and privileged polycyclic structures. Currently, only a handful of processes have been demonstrated, leaving the area ripe for exploitation.

\section{Applications from the Electronic Properties of Benzo[1,2,3]dithiazoles}

While having been first noted in early research that the Herz compounds were incredibly intense dyes, further investigation into their electronic properties has only recently been undertaken. It was the realisation that benzodithiazole structures can form stable radicals that are nevertheless easy to oxidise back to the ionic 'Herz salt' that has increased scientific interest in this area.

The promising electronic properties of these entities were demonstrated by synthesising coordination complexes, such as the lithium bound system (Figure 11) [95]. The dithiazole rings have large spin densities about the $\mathrm{N}$ and $\mathrm{S}$ atoms, hence engaging in intermolecular interactions [95]. This makes such compounds intriguing aromatic ligands for the preparation of new metal complexes, especially if an existing metal chelator, such as $o$-quinone derivatives, is used as the starting material.

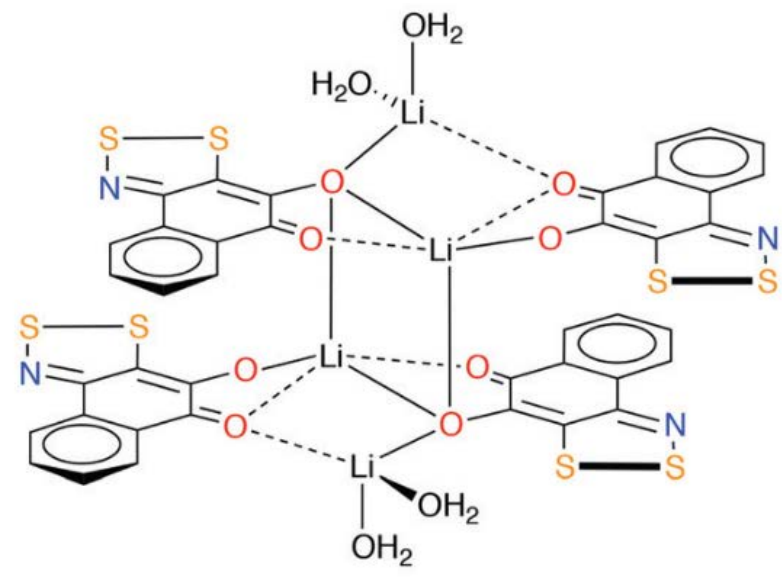

Figure 11. The structure of a metal-benzodithiazole complex [95].

\subsection{Legacy, Visible-Light Dyes}

A prominent property arising from the highly conjugated $\pi$-systems and intense electromagnetic absorptions within the visible light range is the generation of intensely coloured compounds. The benzodithiazole compounds were one of many classes of intensely coloured compounds discovered by Richard Herz when investigating the reaction of small aromatic compounds with polysulfide moieties [19]. While the benzodithiazoles were core in the research of Herz that led to scores of new dye compounds, $[19,96,97]$ 
they were mainly utilised as feedstocks for other molecules in which the final structures had lost their benzodithiazole moiety. Indeed, although benzodithiazoles are described as dye substances in several patents [18], there appears no evidence they have ever been commercialised. Nevertheless, the importance of the Herz reaction in supporting these discoveries is evident from the fact that many patented dyes [96,97] in the 1920s and 30s contain para-chlorides in the structure, doubtlessly introduced during the Herz reaction (Figure 12).<smiles>Cc1cc(Cl)cc2c1C(=O)/C(=C1/Sc3cc(Cl)cc(C)c3C1=O)S2</smiles>

Dimethyl-6.6'-dichloro-thioindigo (1931)<smiles></smiles>

Figure 12. Two patented dye molecules that were derived from Herz reaction products, indicating the prevalent chloride substitution [96,97].

\subsection{Near-Infrared Dyes}

In contrast to earlier works relying on benzodithiazoles as merely synthetic intermediates, recent studies suggest that compounds bearing benzodithiazole moieties indeed have applicability due to their novel absorption and redox properties. Starting with the readily radicalised, anti-aromatic structures (e.g., 27a, Scheme 28) first synthesised by Reed et al. [98] using triphenylantimony to transform the Herz reaction products, in extension, Makarov et al. have synthesised a range of near-infrared dyes. Two such examples, 27b and 27c, are shown (Scheme 28) [11]. Compounds with lower bandgap absorptions in the near-IR range (typically $<1.6 \mathrm{eV}$ ) are particularly sought after in the development of photodetectors, photovoltaic cells and ambipolar field-effect transistors [99,100]. Other poly-heteroaromatics, including benzo[1,3,2]dithiazoles, are common in such applications [99], although what is particular about these benzo[1,2,3]dithiazole derivatives is the controllable redox activity alongside the near-IR wavelength absorption, giving them the possibility of an end-use in tuneable 'smart materials' [100].

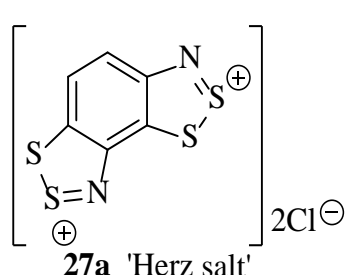

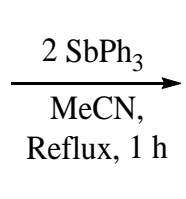<smiles></smiles>

$27 b$, $42 \%$ yield

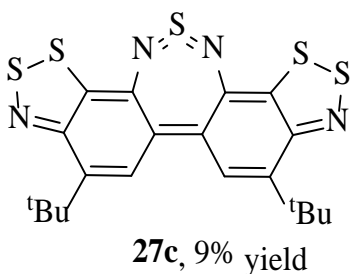

27c, $9 \%$ yield

Scheme 28. The synthetic procedure of Makarov et al. to form the active benzodithiazole-containing compounds [11].

Mayer [33] had shown previously that phenazine derivatives could be accessed through the oxidised radical intermediates (Section 4.3). Correspondingly, these new compounds $27 \mathrm{~b}-\mathrm{c}$ were thermally stable to over $200^{\circ} \mathrm{C}$, and the yield for the phenazine is similarly quite high considering the complexity of the active compound. The redox behaviour of the compounds was studied, finding that up to five different electronic states could be accessed. Each state having distinct absorption in the near-IR to UV range, consistent with the desire to produce compounds with tuneable absorption properties.

\subsection{Semiconductors}

An organic solid can be a semiconductor if the energy of its band gap $\left(E_{g}\right)$ between its occupied and vacant electronic states is sufficiently small that the vacant states can be occupied thermally. If $\mathrm{E}_{\mathrm{g}}$ is too large, then the vacant orbitals cannot be populated without an alternative energy input (such as radiation) and the material acts as an insulator. 
Materials with no band gap at all are known as metallic conductors. The discovery of the Herz radicals in the late 1970s did not immediately lead to research into the charge-transfer properties in the solid-state for application as organic conductors. Several studies in the 1980s focussed instead on the alternative benzo[1,3,2]dithiazoles [101-103]. Given the extensive research within the field in the 1980s and 90s [104], it is somewhat surprising that the charge-transfer chemistry of benzo[1,2,3]dithiazoles was seemingly not considered until a computational investigation by Genin and Hoffmann [105] (1997) and later an experimental one by Barclay et al. [98] (1998). We have discussed how these anti-aromatic structures in the neutral form are easily oxidised to form stable radical cations (Section 2.6), and in particular cases, this can generate conductivity, depending on the solid-state arrangement. Different solids, perchlorate and $\mathrm{FSO}_{3}{ }^{-}$salts (28a-d), were prepared by Barclay et al. (in either a 1:1 or 3:2-organic compound: inorganic ion ratio), and their conductivities were measured in the order of $10^{-2} \mathrm{~S} \mathrm{~cm}^{-1}$ for the $3: 2$ complexes (sufficient to class them as solid semiconductors, 28b, 28d, Table 4). Separately, a third solid (28e) was formed with naphtho[2,1-d:6,5-dA]bis([1,2,3]dithiazole) and $\mathrm{BF}_{4}$ counter ion (3:2 ratio) and the conductivity was of the same $\left(10^{-2} \mathrm{~S} \mathrm{~cm}^{-1}\right)$ order of magnitude (Table 4) [53].

Table 4. Five different solids based on the benzo[1,2,3]dithiazole moiety and their measured conductivities at room temperature $[53,98]$.

\begin{tabular}{ll} 
Solid Formula & Measured Conductivity $/ \mathrm{S} \mathrm{cm}^{-1}$ (One Significant Figure) \\
\hline
\end{tabular}

$\underbrace{S}_{28 \mathrm{~b}}$

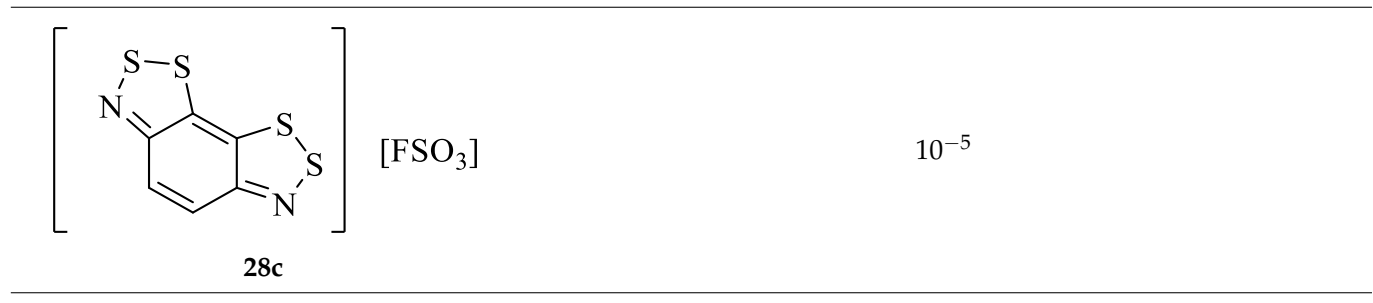
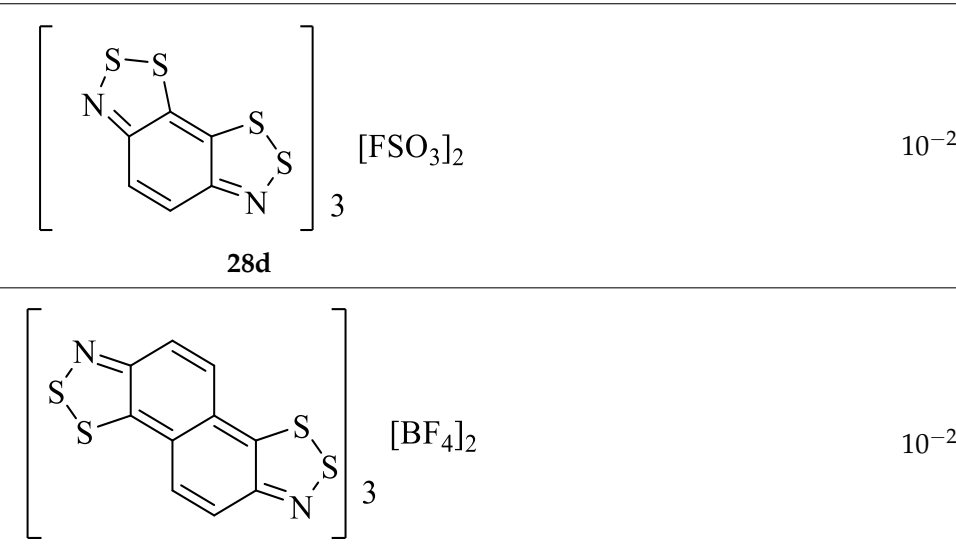
Subsequent findings relating to the electronic properties of this series were reviewed by Lonchakov et al. [48] supported by a computational study [106]; the properties and behaviour of such benzo[1,2,3]dithiazole structures are compared to other N-heterocyclic electron acceptors. Oakley et al. first reported an experimental investigation into the electrochemical potential of benzo[1,2,3]dithiazoles and later isolated a Zwitterionic benzobis $[1,2,3]$ dithiazole compound (29d, Scheme 29), a privileged $17 \pi$ system [54]. The new Zwitterionic benzodithiazole (29d), crystallised in the absence of other counter ions or solvates, arranged into flat sheets of a 'brick wall' motif, which possessed conductivity of about $10^{-3} \mathrm{~S} \mathrm{~cm}^{-1}$ at room temperature and pressure (Figure 13). Remarkably, under a pressure of $8 \mathrm{GPa}$, the material's band gap decreased further, and essentially, it became a metallic conductor, with a conductivity of $>10 \mathrm{~S} \mathrm{~cm}^{-1}$. The preparation of the parent benzobis [1,2,3]dithiazole $(\mathbf{2 9 b})$ is synthetically noteworthy as it required the unusual installation of two benzo[1,2,3]dithiazole rings via a diaminobenzene (29a) starting material with disulfur dichloride (Scheme 19). The conversion to the 'Herz radical' form (29c) electrochemically [44] or to the zwitterionic form (29d) by reacting with a proton sponge is readily mediated (Scheme 29) [54].<smiles>[X]c1cc(N)c(O)c(N)c1</smiles>

29a

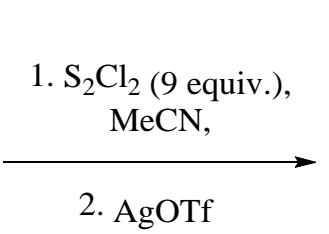<smiles>[X]C1=C2SN=C2C(=O)C2NCSC12</smiles>

29c, Herz radical

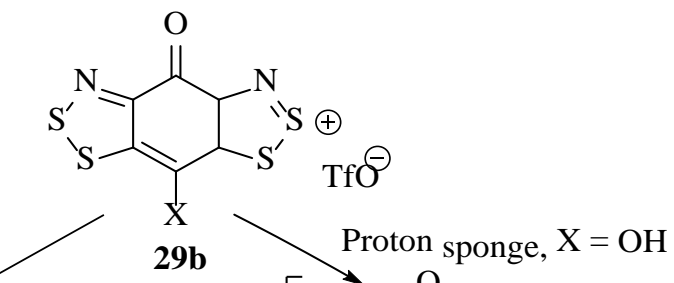

29b<smiles>O=C1C2=C(NCCS2)C(=O)C2S[Se]=NC12</smiles>

29d, Zwitterion form<smiles>CS1=NC2C(=O)C3=N[As](C)SC3=C(O)C2S1</smiles>

$\Theta$

Scheme 29. The synthesis of the parent Herz salt and continuation to either radical or Zwitterionic forms $[44,54]$.

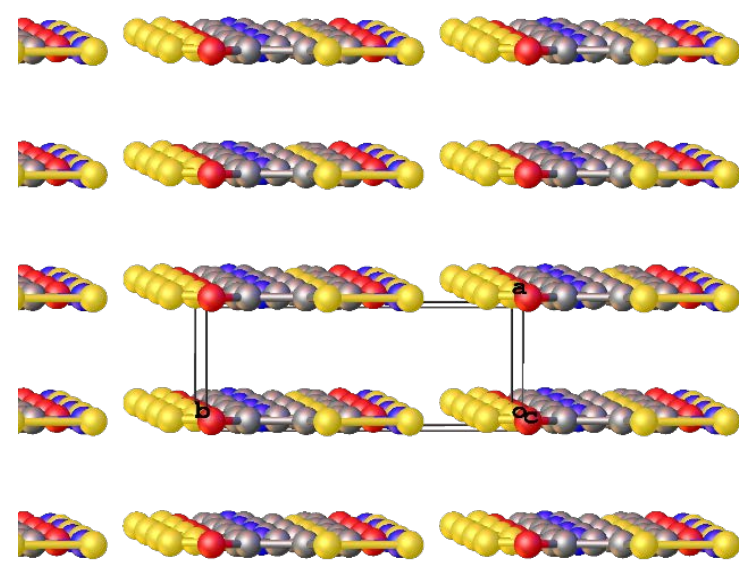

(a)

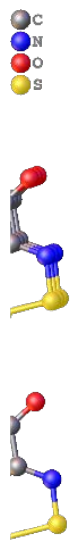

$-$
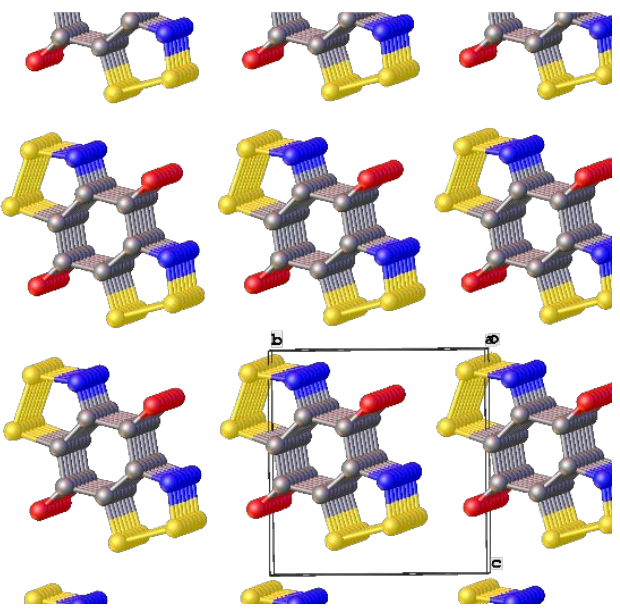

(b)

Figure 13. The crystal structures and unit cells of the Zwitterionic product (Scheme 29) synthesised by Oakley et al. in the solid state. (a) showing the perfectly-stacked flat sheets of molecules and (b) looking 'through' the sheets. The distance between the sheets (or the length of the shortest edge in the unit cell) is $3.0 \AA$ and the space group is Cmc2 ${ }_{1}$ [107]. 
Subsequently, the same group synthesised the equivalent to molecule $29 \mathrm{~d}$, but with the 2-positions of the dithiazole rings substituted with selenium, rather than sulphur (29e, Figure 14) [108]. The intention was to form a crystalline polymorph with perfectly stacked sheets, analogous to their above example (Figure 13), though ultimately, no such polymorph could be formed. Instead, solids of three alternative phases were synthesised in space groups $\mathrm{P} 2{ }_{1} / \mathrm{c}$ and $\mathrm{R} 3 \mathrm{c}$ (Figure 14, the thiazole rings are slightly out-of-plane with the benzene ring) with conductivities measured. At room temperature and pressure, the $\mathrm{P} 2{ }_{1} / \mathrm{c}$ polymorph was a Mott insulator with a low conductivity at $10^{-5} \mathrm{~S} \mathrm{~cm}^{-1}$. The R3c phase fared better at $10^{-2} \mathrm{~S} \mathrm{~cm}^{-1}$ and, similarly to the $\mathrm{Cmc}_{1}$ sulphur analogue (Figure 13), became a metallic conductor at $6 \mathrm{GPa}$.

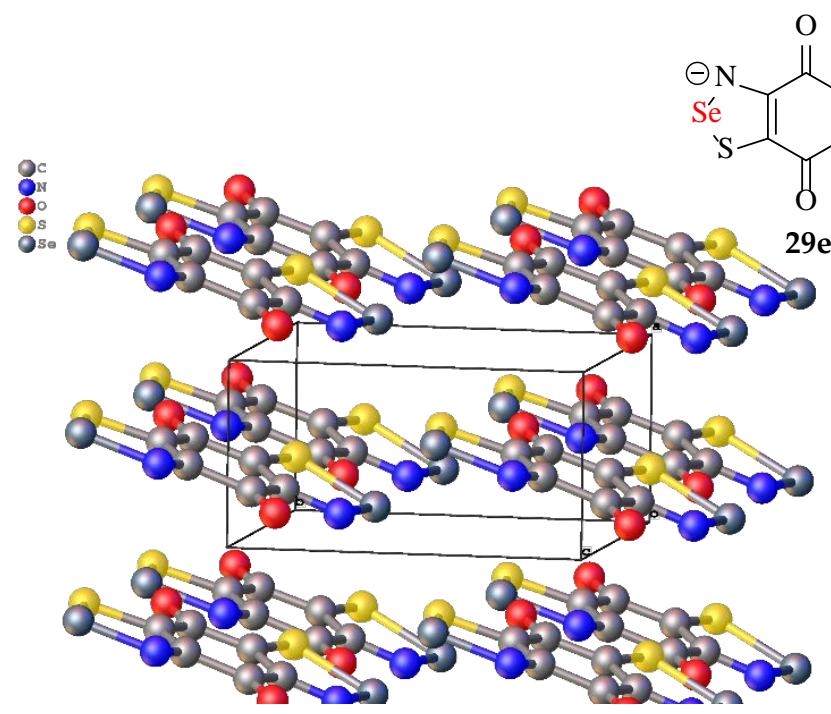

(a)

(b)

Figure 14. Two crystal structures and unit cells of the selenium Zwitterionic product (29e) synthesised by Oakley et al. in the solid-state [108]: (a) the P2 1 /c (mott insulator) phase [109] and (b) the R3c (semiconductive) phase [110].

A parallel investigation that included solids based on the benzobis[1,2,3]dithiazole neutral radicals (Scheme 29) was performed [111-115]. The desired 'brick wall' sheet structure (space group $\mathrm{Cmc}_{1}$, as in Figure 13) was formed with the fluoro substituent (30b, Table 5), which possessed marginally improved room-temperature conductivity $\left(\right.$ at $\left.2 \times 10^{-2} \mathrm{~S} \mathrm{~cm}^{-1}\right)$ compared to the Zwitterionic benzobisdithiazole solids (Scheme 29) $[44,54,108]$. The structures bearing bulkier substituents (30a (OAc), $\mathbf{3 0 f}(\mathrm{OMe})$ and $\mathbf{3 0} \mathrm{g}(\mathrm{SMe})$ ) instead formed $\mathrm{P} 2_{1} / \mathrm{c}$ crystals (as in Figure 14a) and thus acted as Mott insulators. Seven different benzobisdithiazoles were synthesised as the Herz salt, and each could be reduced to the neutral radical $(\mathbf{3 0 a}-\mathbf{g}$, following an ion-exchange) electrochemically [111]; over time, a library of semi-conducting radical solids was built up across the publications (Table 5). 
Table 5. The synthesis of conducting solid benzobis[1,2,3]dithiazoyl radicals across several publications by Oakley et al. [55,111-115].

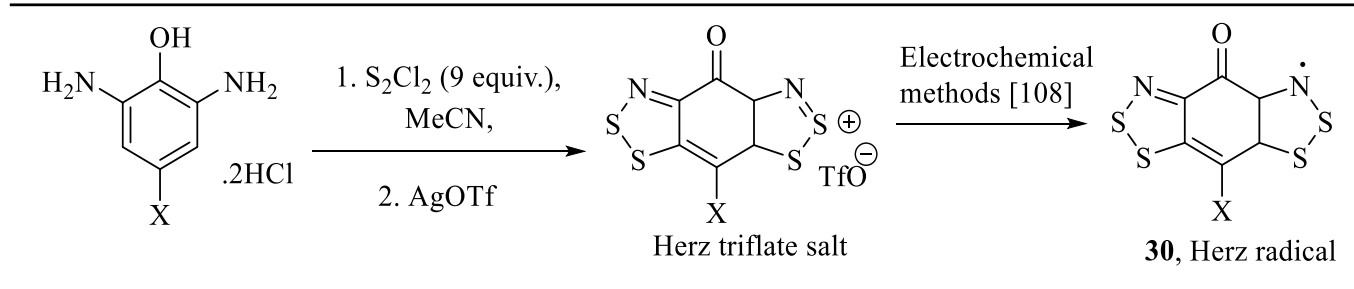<smiles>CC(=O)OC1=C2SN=C2C(=O)C2SSNC12</smiles>

30a, $93 \%^{\mathrm{a}}$<smiles>O=C1C2=NSSC2=C(c2ccccc2)C2SSNC12</smiles>

30d, $88 \%$<smiles>CSC1=C2SN=C2C(=O)C2NSCC12</smiles>

30g, $72 \%$<smiles></smiles>

30b, $75 \%$<smiles></smiles>

30e, $81 \%$<smiles>CN1C2=NSSC2=C(Cl)C2SSNC21</smiles>

30h, $89 \%{ }^{b}$<smiles></smiles>

30c, $88 \%$<smiles></smiles>

30f, $81 \%^{\mathrm{a}}$<smiles>CCN1C2=NSSC2=C(Cl)C2SSNC21</smiles>

30i, $84 \%^{\mathrm{b}}$

a Synthesised using a quinone intermediate and then reduced with an electrochemical method [111]. ${ }^{\mathrm{b}}$ Reduced from the $\mathrm{SbF}_{6}$ salt (rather than $\mathrm{TfO}$ ) with a Fe-Cp complex rather than electrochemically [55]. Percentages refer to pure isolated yields for the final reduction (radical formation) step.

\subsection{Photovoltaic or Electrochemical Cells: The Next Application?}

We have seen how organic materials with near-infrared absorption/emission characteristics may have applicability to photovoltaics, as well as elaborated in recent review articles [99,100]. The related benzo[1,3,2]dithiazole moiety appears in recent publications relating to solar cells $[1,116]$. Besides the suggestion by Makarov et al. that these titled $[1,2,3]$ dithiazole structures could feature in photovoltaic materials due to their absorbance characteristics [11], there does not yet appear any further consideration described in the literature. To conclude this section, we note that Zhang and Tuttle have recently published a report into the use of these same compound series as organic electrode materials for a targeted end-use in batteries [117]. Their benzodithiazole-based solid retained $94 \%$ of its initial energy capacity after 400 charges / discharge cycles [117], further demonstrating the potential applicability of these conductive properties.

\section{Conclusions}

Today more than ever, the study of compounds containing benzo[1,2,3]dithiazole groups is an active area in the continuously emerging topics of materials chemistry. The historic Herz reaction remaining the principal method of synthesis. A range of transformations from these Herz compounds has been developed. The ease by which these 
synthesised Herz compounds can radicalise has provided easy access to some very interesting structures with potentially important electronic properties. The authors look forward to the continued appearance of this fascinating ring system in future literature.

Author Contributions: Both authors contributed to, have read and agreed to the published version of the manuscript. A.J.N. performed the investigation and writing of the original draft. I.R.B. performed the supervision, review and editing. Both authors have read and agreed to the published version of the manuscript.

Funding: This research received no external funding.

Data Availability Statement: This article presents no new data of our own. All data presented comes from the indicated sources.

Acknowledgments: In memory of the late inventor of the Herz reaction, Richard Herz (18671936) [19]. Crystal structure images shown throughout are original to the authors and were processed using Olex2 software [118] using the data from the indicated sources.

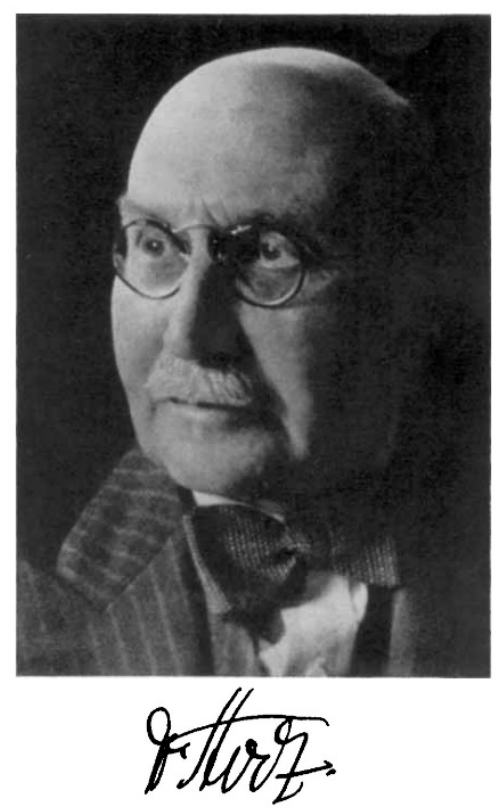

Conflicts of Interest: The authors declare no conflict of interest.

\section{References}

1. Swetha, T.; Karim, M.R.; Alharbi, H.F.; Alharthi, N.H.; Bais, B.; Amin, N.; Akhtaruzzaman, M. Synthesis of New Simple HoleTransport Materials Bearing Benzodithiazole Based Core for Perovskite Solar Cells. Sol. Energy 2019, 194, 431-435. [CrossRef]

2. Baran, D.; Bryant, D.T.J.; Nicola, G.; Troughton, J.R. Radiative Heat-Blocking Materials. World Patent WO2020115663A1, 11 June 2020.

3. Leckie, D.; Stephaniuk, N.T.; Arauzo, A.; Campo, J.; Rawson, J.M. Exploring Through-Bond and Through-Space Magnetic Communication in 1,3,2-Dithiazolyl Radical Complexes. Chem. Commun. 2019, 55, 9849-9852. [CrossRef] [PubMed]

4. Rawson, J.M.; McManus, G.D. Benzo-Fused Dithiazolyl Radicals: From Chemical Curiosities to Materials Chemistry. Coord. Chem. Rev. 1999, 189, 135-168. [CrossRef]

5. Wolmershäuser, G.; Schnauber, M.; Wilhelm, T. Benzo-1,3,2-Dithiazol-2-YL and its Derivatives: A New Class of Donor Molecules for Highly Conducting Charge Transfer Complexes. Mol. Cryst. Liq. Cryst. 1985, 120, 323-326. [CrossRef]

6. Scifinder. A CAS Solution. Available online: https://scifinder.cas.org/scifinder/view/scifinder/scifinderExplore.jsf (accessed on 12 February 2021).

7. Huestis, L.; Emery, I.; Steffensen, E. The Synthesis of 1,3,2-Benzothiazathiolium Salts by the Dehydration of 3 H-1,2,3Benzodithiazole 2-Oxides. J. Heterocycl. Chem. 1966, 3, 518-520. [CrossRef]

8. Bats, J.W.; Fuess, H.; Weber, K.L.; Roesky, H.W. Synthese, Struktur und einige Eigenschaften von 1,2,3-Benzodithiazolium-Salzen. Chem. Ber. 1983, 116, 1751-1755. [CrossRef]

9. Huestis, L.D.; Walsh, M.L.; Hahn, N. The Herz Reaction. The Formation and Hydrolysis of Herz Compounds. J. Org. Chem. 1965, 30, 2763-2766. [CrossRef] 
10. Akulin, Y.I.; Gel'mont, M.M.; Strelets, B.K.; Éfros, L.S. Structures and Reactivities of Benzo-1,2,3-Dithiazolium Salts and Their Selenium Analogs. Chem. Heterocycl. Compd. 1978, 14, 733-737. [CrossRef]

11. Volkova, Y.M.; Makarov, A.Y.; Zikirin, S.B.; Genaev, A.M.; Bagryanskaya, I.Y.; Zibarev, A.V. 3,1,2,4-Benzothiaselenadiazine and Related Heterocycles: Synthesis and Transformation into Herz-Type Radicals. Mendeleev Commun. 2017, 27, 19-22. [CrossRef]

12. Makarov, A.Y.; Volkova, Y.M.; Shundrin, L.A.; Dmitriev, A.A.; Irtegova, I.G.; Bagryanskaya, I.Y.; Shundrina, I.K.; Gritsan, N.P.; Beckmann, J.; Zibarev, A.V. Chemistry of Herz Radicals: A New Way to Near-IR Dyes with Multiple Long-Lived and Differently-Coloured Redox States. Chem. Commun. 2020, 56, 727-730. [CrossRef]

13. Strelets, B.K.; Éfros, L.S. Structure of Benzothiazolium Compounds (Herz's Compounds) and Their Hydrolysis Products. J. Org. Chem. USSR 1969, 5, 151-154.

14. Neo, A.G.; Carrillo, R.M.; Marcos, C.F. A Straightforward Synthesis of 2-Aminobenzothiazoles from Herz Compounds. Org. Biomol. Chem. 2011, 9, 4850-4855. [CrossRef] [PubMed]

15. Van Snick, W.; Aibuldinov, Y.K.; Dehaen, W. An Efficient Synthetic Route Towards Novel Thienobenzothiazoles, Thienobenzothiazepines, and Thienobenzothiazines. Tetrahedron 2013, 69, 4176-4184. [CrossRef]

16. Barclay, T.M.; Cordes, A.W.; Goddard, J.D.; Mawhinney, R.C.; Oakley, R.T.; Preuss, K.E.; Reed, R.W. Benzo-Bridged Bis(1,2,3dithiazoles) and their Selenium Analogues. Preparation, Molecular and Electronic Structures, and Redox Chemistry. J. Am. Chem. Soc. 1997, 119, 12136-12141. [CrossRef]

17. Makarov, A.Y.; Chulanova, E.A.; Semenov, N.A.; Pushkarevsky, N.A.; Lonchakov, A.V.; Bogomyakov, A.S.; Irtegova, I.G.; Vasilieva, N.V.; Lork, E.; Gritsan, N.P.; et al. QITJIO: 6H-1,2,3-Benzodithiazol-6-Ylidenemalononitrile Tetrahydrofuran Solvate. Exp. Cryst. Struct. Determ. 2013, 946863. [CrossRef]

18. Herz, R. Verfahren zur Darstellung von Schwefel- und Stickstoffhaltigen Kondensationsprodukten der Aromatischen Reihe. German Patent DE360690C, 6 October 1914.

19. Lüttringhaus, A. Richard Herz. 1867-1936. Chem. Ber. 1956, 89, i-x. [CrossRef]

20. Austad, B.C.; Rakitin, O.A. Disulfur Dichloride. In Encyclopedia of Reagents for Organic Synthesis; John Wiley \& Sons, Ltd.: Chichester, UK, 2011; Volume 1, pp. 1-9. ISBN 1915941016.

21. Sawhney, S.N.; Sharma, P.; Bajaj, K.; Gupta, A. A New Synthesis of 2-Arylbenzothiazoles from 1,2,3-Benzodithiazole-2-Oxides. Synth. Commun. 1993, 23, 263-270. [CrossRef]

22. Hope, P.; Wiles, L.A. The Action of Sulphur Monochloride on Aromatic Primary Amines: The Herz reaction. J. Chem. Soc. C Org. 1967, 1642-1644. [CrossRef]

23. Warburton, W.K. Arylthiazathiolium Salts And o-Aminoaryl Thiols-The Herz Reaction. Chem. Rev. 1957, 57, 1011-1020. [CrossRef]

24. Claus, A. Mittheilungen aus dem Universitätslaboratorium zu Freiburg i. B. Ber. der Dtsch. Chem. Ges. 1874, 7, 226-237. [CrossRef]

25. Sammes, M.P. Dioxazoles, Oxathiazoles and Dithiazoles. In Comprehensive Heterocyclic Chemistry; Elsevier: Amsterdam, The Netherlands, 1984; Volume 6-7, pp. 897-946. ISBN 9780080965192.

26. Claus, A. Einwirkung von Chlorschwefel auf Anilin. Ber. der Dtsch. Chem. Ges. 1870, 3, 527-528. [CrossRef]

27. Bezzubets, M.; Rozina, V. Issledovanie v Oblasti Kislotnykh Antrakhinonnykh Soedinenii. 1. O Vliyanii Zamestitelei v Fenilaminnom Radikale Kislotnykh Antrakhinonnykh Soedinenii na Ikh Svoistva. Zhurnal Prikl. Khimii 1948, 21, 1152-1161.

28. García-Valverde, M.; Torroba, T. Heterocyclic Chemistry of Sulfur Chlorides-Fast Ways to Complex Heterocycles. Eur. J. Org. Chem. 2006, 2006, 849-861. [CrossRef]

29. Gompper, R.; Euchner, H.; Kast, H. Umsetzungen $\alpha . \beta$-ungesättigter $\beta$-Amino- und $\beta$-Hydroxy-carbonylverbindungen mit Dischwefeldichlorid und verwandten Verbindungen. Justus Liebigs Ann. Chem. 1964, 675, 151-174. [CrossRef]

30. Inagaki, Y.; Okazaki, R.; Inamoto, N. Chemistry of N-Thiosulfinylanilines. II. Thermolysis and Photolysis of N-Thiosulfinylanilines. Bull. Chem. Soc. Jpn. 1979, 52, 2002-2007. [CrossRef]

31. Inagaki, Y.; Okazaki, R.; Inamoto, N. Chemistry of N-Thiosulfinylanilines. I. Reactions of Sterically Hindered Anilines with Sulfur Chlorides. Preparation of N-Thiosulfinylanilines. Bull. Chem. Soc. Jpn. 1979, 52, 1998-2001. [CrossRef]

32. Inagaki, Y.; Okazaki, R.; Inamoto, N.; Yamada, K.; Kawazura, H. Chemistry of N-Thiosulfinylanilines. III. Thiosulfinylamine5H-1,2,3-Dithiazole Equilibrium as Studied by NMR Spectroscopy. Bull. Chem. Soc. Jpn. 1979, 52, 2008-2009. [CrossRef]

33. Mayer, R. S,N-Compounds via Amines and Sulphur Halides. Phosphorus Sulfur Relat. Elem. 1985, 23, 277-296. [CrossRef]

34. Chenard, B.L. Pyrazolothiadiazoles from 3-Aminopyrazoles: The Hetero-Herz Reaction. J. Org. Chem. 1984, $49,1224-1227$. [CrossRef]

35. Iwasaki, F. The Structures of 2,4,6-Tri-tert-butyl-7,8,9-dithiazabicyclo[4.3.0]nona-1(9),2,4-triene and its 7-Oxide. Acta Crystallogr. Sect. B Struct. Crystallogr. Cryst. Chem. 1980, 36, 1466-1471. [CrossRef]

36. Inagaki, Y.; Okazaki, R.; Inamoto, N. Preparation of a Sterically Hindered N-Thiosulfinylaniline and its Equilibrium with a Novel Heterocycle, 5h-1,2,3-Dithiazole. Tetrahedron Lett. 1975, 16, 4575-4578. [CrossRef]

37. Barton, D.H.R.; Robson, M.J. Preparation and Properties of p-Dimethylamino-N-Thiosulphinylaniline. J. Chem. Soc. Perkin Trans. 1 1974, 1245-1247. [CrossRef]

38. Okazaki, R.; Inoue, K.; Inamoto, N. Reactions of Ketone Hydrazones and $\beta$-Keto Enamines with Disulfur Dichloride. New Synthesis of Thioketones and 5H-1,2,3-Dithiazoles. Bull. Chem. Soc. Jpn. 1981, 54, 3541-3545. [CrossRef]

39. Iwasaki, F. The Crystal and Molecular Structure of 2,4-Di-tert-butyl-6-methyl-N-thiosulphinylaniline. Acta Crystallogr. Sect. B Struct. Crystallogr. Cryst. Chem. 1979, 35, 2099-2103. [CrossRef] 
40. Koutentis, P.A.; Rees, C.W. Reaction of Herz Salts with Malononitrile: A General Route to (6H-1,2,3-Benzodithiazol-6ylidene)malononitriles. J. Chem. Soc. Perkin 1 2002, 3, 315-319. [CrossRef]

41. Mayer, R.; Domschke, G.; Bleisch, S.; Bartl, A. 1,2-Thiazet-2-yle, eine Neue Klasse Stabiler Radikale. Tetrahedron Lett. 1978, 19, 4003-4006. [CrossRef]

42. Fabian, J.; Mayer, R.; Bleisch, S.; Zahradník, R. Electronic Excitation of Organosulfur Radicals. Phosphorus Sulfur Relat. Elem. 1982, 13, 107-117. [CrossRef]

43. Bartl, A.; Siegfried, B.; Guenter, D.; Mayer, R. Verfahren Zur Erzeugung Persistenter(Stabiler)1,2,3-Dithiazolyle. German Patent DD156183A1, 4 August 1981.

44. Yu, X.; Mailman, A.; Lekin, K.; Assoud, A.; Dube, P.A.; Oakley, R.T. A Bimodal Oxobenzene-Bridged Bisdithiazolyl Radical Conductor. Cryst. Growth Des. 2012, 12, 2485-2494. [CrossRef]

45. Chulanova, E.A.; Irtegova, I.G.; Vasilieva, N.V.; Bagryanskaya, I.Y.; Gritsan, N.P.; Zibarev, A.V. Novel Long-Lived N-Heterocyclic Radical Anion: A Hybrid of 1,2,5-Thiadiazo- and 1,2,3-Dithiazolidyls. Mendeleev Commun. 2015, 25, 336-338. [CrossRef]

46. Parikh, K.; Warren, C.; Caracio, R. Education on Reactive Oxygen Species to Lay the Foundation for Understanding Therapeutic Advances in Anticancer Therapy. J. Clin. Oncol. 2021, 39, 478. [CrossRef]

47. Makarov, A.Y.; Chulanova, E.A.; Semenov, N.A.; Pushkarevsky, N.A.; Lonchakov, A.V.; Bogomyakov, A.S.; Irtegova, I.G.; Vasilieva, N.V.; Lork, E.; Gritsan, N.P.; et al. A Novel Sulfur-Nitrogen $\pi$-Heterocyclic Radical Anion, (6H-1,2,3-Benzodithiazol-6ylidene)malononitrilidyl, and its Homo- and Heterospin Salts. Polyhedron 2014, 72, 43-49. [CrossRef]

48. Lonchakov, A.V.; Rakitin, O.A.; Gritsan, N.P.; Zibarev, A.V. Breathing Some New Life into an Old Topic: Chalcogen-Nitrogen $\pi$-Heterocycles as Electron Acceptors. Molecules 2013, 18, 9850-9900. [CrossRef] [PubMed]

49. Ried, W.; Valentin, J.; Schubert, M. The Herz Reaction with 1,5-Diaminonaphthalene. Angew. Chem. Internat. Ed. $1965,4,711$.

50. Makarov, A.Y.; Zhivonitko, V.V.; Makarov, A.G.; Zikirin, S.B.; Bagryanskaya, I.Y.; Bagryansky, V.A.; Gatilov, Y.V.; Irtegova, I.G.; Shakirov, M.M.; Zibarev, A.V. Interaction of 1,3,2,4-benzodithiadiazines and their 1-Se congeners with Ph3P and some properties of the iminophosphorane products. Inorg. Chem. 2011, 50, 3017-3027. [CrossRef]

51. Makarov, A.Y.; Zhivonitko, V.V.; Makarov, A.G.; Zikirin, S.B.; Bagryanskaya, I.Y.; Bagryansky, V.A.; Gatilov, Y.V.; Irtegova, I.G.; Shakirov, M.M.; Zibarev, A.V. EWADAI: Benzo[1,2-c:3,4-c':5,6-c"']tris[1,2,5]thiadiazole. Exp. Cryst. Struct. Determ. 2011, 769835. [CrossRef]

52. Maier, G.; Schrot, J.; Reisenauer, H.P.; Janoschek, R. C5S2 (1,2,3,4-Pentatetraen-1,5-dithion), ein neues Sulfid des Kohlenstoffs. Chem. Ber. 1990, 123, 1753-1756. [CrossRef]

53. Barclay, T.M.; Burgess, I.J.; Cordes, A.W.; Oakley, R.T.; Reed, R.W. Preparation and Structural Characterization of Naphtho[2,1d:6,5-d']bis([1,2,3]dithiazole) NT and $\pi$-Stacked Mixed Valence Salt [NT]3[BF4]2. Chem. Commun. 1998, 1939-1940. [CrossRef]

54. Mailman, A.; Leitch, A.A.; Yong, W.; Steven, E.; Winter, S.M.; Claridge, R.C.M.; Assoud, A.; Tse, J.S.; Desgreniers, S.; Secco, R.A.; et al. The Power of Packing: Metallization of an Organic Semiconductor. J. Am. Chem. Soc. 2017, 139, 2180-2183. [CrossRef]

55. Beer, L.; Britten, J.F.; Brusso, J.L.; Cordes, A.W.; Haddon, R.C.; Itkis, M.E.; MacGregor, D.S.; Oakley, R.T.; Reed, R.W.; Robertson, C.M. Prototypal Dithiazolodithiazolyl Radicals: Synthesis, Structures, and Transport Properties. J. Am. Chem. Soc. 2003, 125, 14394-14403. [CrossRef]

56. Röder, L.; Nicholls, A.J.; Baxendale, I.R. Flow Hydrodediazoniation of Aromatic Heterocycles. Molecules 2019, 24, 1996. [CrossRef]

57. Reitzenstein, F. Verfahren zur Darstellung von Azoxyverbindungen. J. Für Prakt. Chem. 1910, 82, 252-270. [CrossRef]

58. Polo, C.; Ramos, V.; Torroba, T.; Rakitin, O.A.; Rees, C.W. One Pot Synthesis of 1,2,3,-Benzodithiazol-6-ones. Tetrahedron 1998, 54, 223-232. [CrossRef]

59. Mayer, R.; Gúnter, D.; Bleisch, S.; Fabian, J.; Bartl, A.; Stasko, A. 1,2,3-Dithiazolyle, Eine Neue Klasse Persistenter Radikale. Collect. Czechoslov. Chem. Commun. 1984, 49, 684-703. [CrossRef]

60. Belica, P.S.; Manchand, P.S. A Convenient Synthesis of 2-Aminonaphthalene-1-thiol. Synthesis 1990, 1990, 539-540. [CrossRef]

61. Merck. Available online: https://www.sigmaaldrich.com/catalog/search/substructure/SubstructureSearchResultsPage (accessed on 5 February 2021).

62. Wang, P.; Zhao, S.; Liu, Z.; Cui, P.; Liang, Z. A Green Industrialized Preparation Method of Rubber Peptizer DBD. Chinese Patent CN 104774165, 16 March 2015.

63. Mayuri, P.; Kumar, K.; Goud, N.S. Achaiah Review on 2-Substituted Benzothiazole: Diversity of Synthestic Methods and Biological Activities. Int. J. Pharm. Sci. Res. 2015, 7, 1375-1385.

64. Hojo, M.; Takagi, Y.; Ogata, Y. Kinetics of the Reduction of Nitrobenzenes by Sodium Disulfide. J. Am. Chem. Soc. 1960, 82, 2459-2462. [CrossRef]

65. Huber, D.; Andermann, G.; Leclerc, G. Selective Reduction of Aromatic/Aliphatic Nitro Groups by Sodium Sulfide. Tetrahedron Lett. 1988, 29, 635-638. [CrossRef]

66. McLaughlin, M.A.; Barnes, D.M. A Practical and Selective Reduction of Nitroarenes using Elemental Sulfur and Mild Base. Tetrahedron Lett. 2006, 47, 9095-9097. [CrossRef]

67. Pradhan, N.C.; Sharma, M.M. Reactions of Nitrochlorobenzenes with Sodium Sulfide: Change in Selectivity with Phase-Transfer Catalysts. Ind. Eng. Chem. Res. 1992, 31, 1606-1609. [CrossRef]

68. Nicholls, A.J. Investigation of New Routes to Benzothiazole or 2-Aminothiophenol as Feedstocks for the Synthesis of Pepton ${ }^{\mathrm{TM}}$. Ph.D. Thesis, University of Durham, Durham, UK, 2021. 
69. Rajeswari, T.; Rekha, T.; Dinneswara Reddy, G.; Padmaja, A.; Padmavathi, V. Synthesis and Antibacterial Activity of Benzazolyl Azolyl Sulfamoyl Acetamides. J. Heterocycl. Chem. 2019, 56, 2449-2459. [CrossRef]

70. Song, Y.; Huang, Z. Carbapenem Derivatives Containing Formamide Heterocyclic Mercaptopyrrolidine. Chinese Patent CN 101613352A, 27 March 2009.

71. Piscitelli, F.; Ballatore, C.; Smith, A.B. Solid Phase Synthesis of 2-Aminobenzothiazoles. Bioorg. Med. Chem. Lett. 2010, 20, 644-648. [CrossRef]

72. Bondock, S.; Fadaly, W.; Metwally, M.A. Recent Trends in the Chemistry of 2-Aminobenzothiazoles. J. Sulfur Chem. 2009, 30, 74-107. [CrossRef]

73. Dadmal, T.L.; Katre, S.D.; Mandewale, M.C.; Kumbhare, R.M. Contemporary Progress in the Synthesis and Reactions of 2-Aminobenzothiazole: A Review. New J. Chem. 2018, 42, 776-797. [CrossRef]

74. Ulrich, H. Product Class 18: Benzothiazoles and Related Compounds. In Category 2, Hetarenes and Related Ring Systems; Schaumann, Ed.; Georg Thieme Verlag: Stuttgart, Germany, 2002.

75. Leaper, J.M.F. Some Heterocyclic Derivatives Of Diphenyl. J. Am. Chem. Soc. 1931, 53, 1891-1896. [CrossRef]

76. Herz, R. Verfahren Zur Herstellung von schwefel- und stickstoffhaltigen Kondensationprodukten der aromatischen Reihe. German Patent DE487849C, 5 December 1929.

77. Booth, G. Nitro Compounds, Aromatic. In Ullmann's Encyclopedia of Industrial Chemistry; Wiley-VCH Verlag GmbH \& Co. KGaA: Weinheim, Germany, 2000; Volume 24, pp. 392-448. ISBN 9783924063825.

78. Strelets, B.K.; Éfros, L.S.; Akulin, Y.I. Reaction of Benzo-1,2,3-Dithiazolium Salts with Aromatic Amines. Chem. Heterocycl. Compd. 1976, 12, 161-163. [CrossRef]

79. Naitoh, T.; Horie, T.; Nagato, S.; Kagaya, T.; Kubota, A.; Akasaka, K. Application of Pharmacokinetic Studies to a Novel Antidepressant, E2011. Xenobiotica 1994, 24, 819-826. [CrossRef]

80. Sheldon, L.J. Combination Therapy for Dementia, Depression and Apathy. U.S. Patent 8,703,764, 22 April 2014.

81. Sciences, B. NVP-231-CAS 362003-83-6. Available online: https:/ /www.bocsci.com/nvp-231-cas-362003-83-6-item-84-272254. html?msclkid=7f9d3e1270781ed1eb4f5e3740f151e7\&utm_source=bing\&utm_medium=cpc\&utm_campaign=Bocsci-Inhibitor\& utm_term=362003-83-6\&utm_content=362003-83-6 (accessed on 11 February 2021).

82. Nakamura, H.; Murayama, T. Pharmaceutical Composition For Preventing Or Treating Niemann-Pick Disease Type C. Japanese Patent JP2017071576A, 13 April 2017.

83. Fathman, G.C.; Soares, L.R. Combination Of Low Dose Il-2 And An Inhibitor Of Treg Il-2r Desensitization To Treat Autoimmune And Allergic Inflammatory Diseases. World Patent WO2018218119A1, 25 May 2018.

84. Avelar, R.; Maiti, A.; Tolekis, P.M.; Cashman, J.D.; Gravett, D.M. Sutures and Anti-Scarring Agents. World Patent WO2007089878A2, 9 August 2007.

85. Johnson, J.A.; Pi, Z.; Qiao, J.X.; Kim, S.-H.; Wang, T.C.; Jiang, J.; Finlay, H.; Lloyd, J. Sulfone Amide Linked Benzothiazole Inhibitors Of Endothelial Lipase. U.S. Patent 10,173,991, 8 January 2019.

86. Makarov, A.Y.; Kim, S.N.; Gritsan, N.P.; Bagryanskaya, I.Y.; Gatilov, Y.V.; Zibarev, A.V. Interaction of 1,2,3-benzodithiazolyls (Herz radicals) with dioxygen. Mendeleev Commun. 2005, 15, 14-17. [CrossRef]

87. Mortzfeld, F.B.; Pietruszka, J.; Baxendale, I.R. A Simple and Efficient Flow Preparation of Pyocyanin a Virulence Factor of Pseudomonas aeruginosa. Eur. J. Org. Chem. 2019, 2019, 5424-5433. [CrossRef]

88. Kommi, D.N.; Jadhavar, P.S.; Kumar, D.; Chakraborti, A.K. “All-water” One-Pot Diverse Synthesis of 1,2-Disubstituted Benzimidazoles: Hydrogen Bond Driven 'Synergistic Electrophile-Nucleophile Dual Activation' by Water. Green Chem. 2013, 15, 798-810. [CrossRef]

89. Nicholls, A.J.; Barber, T.; Baxendale, I.R. The Synthesis and Utility of Metal-Nitrosophenolato Compounds-Highlighting the Baudisch Reaction. Molecules 2019, 24, 4018. [CrossRef]

90. Creencia, E.C.; Kosaka, M.; Muramatsu, T.; Kobayashi, M.; Iizuka, T.; Horaguchi, T. Microwave-Assisted Cadogan Reaction for the Synthesis of 2-Aryl-2 H -indazoles, 2-Aryl-1 H -Benzimidazoles, 2-Carbonylindoles, Carbazole, and Phenazine. J. Heterocycl. Chem. 2009, 46, 1309-1317. [CrossRef]

91. Benati, L.; Montevecchi, P.C.; Spagnolo, P. Benzenesulphenanilidyl Radicals. Reactivity of 4'-Methoxy-and 4'-Methoxy-2-nitroBenzenesulphenanilidyl Radicals. J. Chem. Soc. Perkin Trans. 1 1982, 3049-3053. [CrossRef]

92. Zhivonitko, V.V.; Makarov, A.Y.; Bagryanskaya, I.Y.; Gatilov, Y.V.; Shakirov, M.M.; Zibarev, A.V. New Polysulfur-Nitrogen

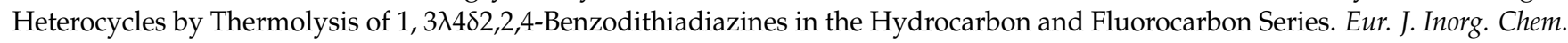
2005, 4099-4108. [CrossRef]

93. Zhivonitko, V.V.; Makarov, A.Y.; Bagryanskaya, I.Y.; Gatilov, Y.V.; Shakirov, M.M.; Zibarev, A.V. MAVQUW: 4,6,7,8,9,11Hexafluoro(1,2,3)dithiazolo(5,4-b)phenothiazine. Exp. Cryst. Struct. Determ. 2006, 268802. [CrossRef]

94. Zhivonitko, V.V.; Makarov, A.Y.; Bagryanskaya, I.Y.; Gatilov, Y.V.; Shakirov, M.M.; Zibarev, A.V. MAVQOQ: 4,5,7,8,9,10Hexafluoro(1,2,3)dithiazolo(4,5-c)phenothiazine. Exp. Cryst. Struct. Determ. 2006, 268801. [CrossRef]

95. Smithson, C.S.; Macdonald, D.J.; Letvenuk, T.M.; Carello, C.E.; Jennings, M.; Lough, A.J.; Britten, J.; Preuss, K.E. A 1,2,3Dithiazolyl-o-Naphthoquinone: A Neutral Radical with Isolable Cation and Anion Oxidation States. Dalt. Trans. 2016, 45, 9608-9620. [CrossRef]

96. Herz, R.; Brunner, W. Verfahren zur Darsellung von rosa bis rot farbenden Kupenfarbstoffen. German Patent DE525668 (C), 7 September 1931. 
97. Herz, R. Verfahren zur Herstellung von Kuepenfarbstoffen. German Patent DE398877C, 29 June 1916.

98. Barclay, T.M.; Cordes, A.W.; Oakley, R.T.; Preuss, K.E.; Reed, R.W. Charge Transfer Chemistry of Benzo[2,1- c:3,4- c ‘ ]bis(1,2,3dithiazole) (BT). Preparation and Structural Characterization of [BT][ClO 4 ] and [BT] 3 [X] 2 (X = ClO 4 - and FSO 3 - ). Chem. Mater. 1999, 11, 164-169. [CrossRef]

99. Dou, L.; Liu, Y.; Hong, Z.; Li, G.; Yang, Y. Low-Bandgap Near-IR Conjugated Polymers/Molecules for Organic Electronics. Chem. Rev. 2015, 115, 12633-12665. [CrossRef]

100. Barbieri, A.; Bandini, E.; Monti, F.; Praveen, V.K.; Armaroli, N. The Rise of Near-Infrared Emitters: Organic Dyes, Porphyrinoids, and Transition Metal Complexes. Top. Curr. Chem. 2016, 374, 1-39. [CrossRef] [PubMed]

101. Williams, K.A.; Nowak, M.J.; Dormann, E.; Wudl, F. Organic Conductors Based on Diradicals: The Benzobisdithiazole (BBDT) System. Synth. Met. 1986, 14, 233-238. [CrossRef]

102. Dormann, E.; Nowak, M.J.; Williams, K.A.; Angus, R.O.; Wudl, F. Benzobisdithiazole (BBDT): An Electron Spin Resonance Study. J. Am. Chem. Soc. 1987, 109, 2594-2599. [CrossRef]

103. Fujita, W.; Awaga, K. Organic Ferromagnetism of Tc $=6.7$ K Driven by Evaporation of Crystal Solvent. Chem. Phys. Lett. 2002, 357, 385-388. [CrossRef]

104. Bryce, M.R. Recent Progress on Conducting Organic Charge-Transfer Salts. Chem. Soc. Rev. 1991, 20, 355-390. [CrossRef]

105. Genin, H.; Hoffmann, R. Theoretical Tinkering: The Search for Magnetically Ordered Organic Polymers Built From Sulfur, Carbon, Nitrogen-Containing Five-Membered Rings. Macromolecules 1998, 31, 444-455. [CrossRef]

106. Lonchakov, A.V. Molecular Design of Precursors of the Chalcogen-Nitrogen Heterocyclic Radical Anions and Theoretical Analysis of the Magnetic Properties of their Salts; Russian Academy of Science: Novosibirsk, Russia, 2013.

107. Mailman, A.; Leitch, A.A.; Yong, W.; Steven, E.; Winter, S.M.; Claridge, R.C.M.; Assoud, A.; Tse, J.S.; Desgreniers, S.; Secco, R.A.; et al. 4,8-dioxo-4,8-dihydrobenzo[1,2-d:5,4-d']bis[1,2,3]dithiazol-6-ium-3-ide. Exp. Cryst. Struct. Determ. 2017, 1566903. [CrossRef]

108. Lekin, K.; Leitch, A.A.; Assoud, A.; Yong, W.; Desmarais, J.; Tse, J.S.; Desgreniers, S.; Secco, R.A.; Oakley, R.T. BenzoquinoneBridged Heterocyclic Zwitterions as Building Blocks for Molecular Semiconductors and Metals. Inorg. Chem. 2018, 57, 4757-4770. [CrossRef]

109. Lekin, K.; Leitch, A.A.; Assoud, A.; Yong, W.; Desmarais, J.; Tse, J.S.; Desgreniers, S.; Secco, R.A.; Oakley, R.T. FIDYUP: 4,8-dioxo-4,8-dihydrobenzo[1,2-d:5,4-d']bis[1,2,3]thiaselenazol-6-ium-3-ide. Exp. Cryst. Struct. Determ. 2018, 1825118. [CrossRef]

110. Lekin, K.; Leitch, A.A.; Assoud, A.; Yong, W.; Desmarais, J.; Tse, J.S.; Desgreniers, S.; Secco, R.A.; Oakley, R.T. FIDYUP01: 4,8-dioxo-4,8-dihydrobenzo[1,2-d:5,4-d']bis[1,2,3]thiaselenazol-6-ium-3-ide. Exp. Cryst. Struct. Determ. 2018, 1825122. [CrossRef]

111. Mailman, A.; Robertson, C.M.; Winter, S.M.; Dube, P.A.; Oakley, R.T. The Importance of Electronic Dimensionality in Multiorbital Radical Conductors. Inorg. Chem. 2019, 58, 6495-6506. [CrossRef] [PubMed]

112. Yu, X.; Mailman, A.; Lekin, K.; Assoud, A.; Robertson, C.M.; Noll, B.C.; Campana, C.F.; Howard, J.A.K.; Dube, P.A.; Oakley, R.T. Semiquinone-Bridged Bisdithiazolyl Radicals as Neutral Radical Conductors. J. Am. Chem. Soc. 2012, 134, 2264-2275. [CrossRef]

113. Mailman, A.; Winter, S.M.; Yu, X.; Robertson, C.M.; Yong, W.; Tse, J.S.; Secco, R.A.; Liu, Z.; Dube, P.A.; Howard, J.A.K.; et al. Crossing the Insulator-to-Metal Barrier with a Thiazyl Radical Conductor. J. Am. Chem. Soc. 2012, 134, 9886-9889. [CrossRef]

114. Yu, X.; Mailman, A.; Dube, P.A.; Assoud, A.; Oakley, R.T. First Semiquinone-Bridged Bisdithiazolyl Radical Conductor: A Canted Antiferromagnet Displaying a Spin-Flop Transition. Chem. Commun. 2011, 47, 4655-4657. [CrossRef] [PubMed]

115. Mailman, A.; Wong, J.W.L.; Winter, S.M.; Claridge, R.C.M.; Robertson, C.M.; Assoud, A.; Yong, W.; Steven, E.; Dube, P.A.; Tse, J.S.; et al. Fine Tuning the Performance of Multiorbital Radical Conductors by Substituent Effects. J. Am. Chem. Soc. 2017, 139, 1625-1635. [CrossRef] [PubMed]

116. Kim, S.W.; Wang, Y.; You, H.; Lee, W.; Michinobu, T.; Kim, B.J. Impact of Incorporating Nitrogen Atoms in NaphthalenediimideBased Polymer Acceptors on the Charge Generation, Device Performance, and Stability of All-Polymer Solar Cells. ACS Appl. Mater. Interfaces 2019, 11, 35896-35903. [CrossRef]

117. Tuttle, M.R.; Zhang, S. Bisthiazolyl Quinones: Stabilizing Organic Electrode Materials with Sulfur-Rich Thiazyl Motifs. Chem. Mater. 2020, 32, 255-261. [CrossRef]

118. Dolomanov, O.V.; Bourhis, L.J.; Gildea, R.J.; Howard, J.A.K.; Puschmann, H. OLEX2: A Complete Structure Solution, Refinement and Analysis Program. J. Appl. Crystallogr. 2009, 42, 339-341. [CrossRef] 